NBER WORKING PAPER SERIES

HOW MUCH BETTER IS BIGGER, FASTER \& CHEAPER? BUYER BENEFITS FROM INNOVATION IN MAINFRAME COMPUTERS IN THE 1980S

Kenneth H. Brown

Shane M. Greenstein

Working Paper No. 5138

\author{
NATIONAL BUREAU OF ECONOMIC RESEARCH \\ 1050 Massachusetts Avenue \\ Cambridge, MA 02138 \\ May 1995
}

We would like to thank Steve Berry, Tim Bresnahan, Jan Brueckner, Rob Feenstra, Zvi Griliches, Harumi Ito, Roger Koenker, Pablo Spiller, Manuel Trajtenberg, Jack Triplett, Wesley Wilson, and many seminar participants for helpful comments and useful conversations. We would also like to thank Computer Intelligence Corporation for their help and Denise Chachere for her valuable research assistance. This work was supported by NSF under IRI92-09321 and by the Institute for Government and Policy Analysis at the University of Illinois. Greenstein also acknowledges the hospitality of CEPR and the Computer Industry Project at Stanford University, where he resided when this paper was completed. All errors are our own. This paper is part of NBER's research program in Productivity. Any opinions expressed are those of the authors and not those of the National Bureau of Economic Research.

(C) 1995 by Kenneth H. Brown and Shane M. Greenstein. All rights reserved. Short sections of text, not to exceed two paragraphs, may be quoted without explicit permission provided that full credit, including (C) notice, is given to the source. 


\title{
HOW MUCH BETTER IS BIGGER, FASTER \& CHEAPER? BUYER BENEFITS \\ FROM INNOVATION IN MAINFRAME COMPUTERS IN THE 1980S
}

\begin{abstract}
This paper develops and estimates cost-of-living indexes (e.g., Fisher and Griliches [1995]) for measuring buyer benefits from technical change in the commercial mainframe computer industry in the 1980s. For this purpose we use a micro-econometric model of demand for product characteristics embodied in a computer system. The model highlights buyers' benefits from technical change when innovation decreases the price of characteristics or increases the range of available characteristics. This exercise follows in the spirit of Trajtenberg [1989].

Our main finding is that our utility-based cost-of-living index declines rapidly (approximately 10-15 percent per year). By historical standards for innovation, this rate is quite fast. Second, our estimates contrast with the rate of change in quality adjusted prices in mainframe computers (approximately 25-30 percent per year). Third, while large price declines induced increases in purchasing, most buyers began the 1980s with a "small" mainframe system and still bought a small system at the end of the decade, even with rapidly declining mainframe prices and large extensions in computing capacity. The experience of the majority outweighs the benefits received by a few (with elastic demand), who took advantage of lower prices and extensions in the product space.
\end{abstract}

Kenneth H. Brown

Department of Economics

University of Northern Iowa

Cedar Falls, IA 50615-0129
Shane M. Greenstein

Department of Economics

University of Illinois, Urbana-Champaign

1206 South Sixth Street

Champaign, IL 61820

and NBER 


\section{Introduction}

As with many information-technology industries, innovation was rampant in the mainframe computer industry of the 1980 s. Broadly speaking, there was a large decline in price per unit of performance across a wide set of computer systems and components, and vendors developed many new computing functions and capabilities. The market experienced remarkable growth, turbulence, and advance associated with hardware architecture redesign, software development, system customization, and learning. In particular, the diffusion and development of innovations associated with "on-line transaction processing" extended the functions of existing large computing facilities, enabling the development of many new goods and new services.

The open debate is about the rate and unevenness of computer users' benefits from these innovations. This paper advances our understanding of this topic by measuring the economic benefits that accrued to computer buyers from technological innovation in the commercial mainframe computer industry in the $1980 \mathrm{~s}$. We model innovations as either a lower price and/or an "extension" of existing capabilities into a new range. Our study estimates the buyer surplus generated from these two types of technical innovation. This exercise follows in the spirit of Trajtenberg [1989], who used a different econometric approach to measure buyer benefits from technical change in CT scanners in the 1970s.

We develop and estimate a micro-econometric model of demand for product features embodied in a computer system. This model is adapted from Rosen [1974], Bartik[1989], and Epple [1989]. Its key feature is that buyers demand a system's processing speed, or memory, and potentially other characteristics. The model highlights buyers' benefits from technical change when innovation decreases the price of characteristics or increases the range of available characteristics. This model's principal strength is that it measures the benefits from technical change in a standard price-theoretic treatment, and suits our data on individual buyers, as described below. We can also easily match the model to standard methods for constructing cost-of-living indexes for measuring buyer benefits from technical change (e.g., Fisher and Griliches [1995]), which provides a simple summary of welfare benefits to users.

We bring rich data to bear on the question of how much computer users benefitted from technical change. We study 21,268 acquisitions of mainframe computers from 1985 to 1991 , more 
than half of all mainframe acquisitions in the U.S. This is as comprehensive a dataset as used in any previous study of large computer buyer demand. ${ }^{1}$ We observe characteristics of the purchases being made and the characteristics of the firms making those purchases. Most published work on the computing market only has data on the set of systems available for sale. Our more detailed data allows us to directly measure the demand for product features at the level of the individual user, construct user-level cost of living indexes, and add up across users to estimate the totoal benefits received market-wide from technological change.

Our indexes and analysis suggests why some mainframe computer buyers benefit greatly from innovation and why others do not. The most important factor is a buyer's elasticity of demand for features of a product, broadly construed. If a buyer's marginal utility in processing speed, for example, does not diminish rapidly, then declines in price per unit of speed will induce large changes in behavior. Thus, we investigate heterogeneity in demand elasticities. Second is whether buyers take advantage of newly created possibilities associated with increasing the range of products available. For example, if a buyer has an elastic demand for more processor speed, a price decline may induce a large increase in desired processor speed, potentially outside the range of processor speed embodied in previously available products. This type of behavior highlights the importance of technical change that extends product capabilities; indeed, it was very important to Trajtenberg's population of CT-scanner buyers. Thus, we also ask: if lower prices induce many buyers to buy more capacity, how many buyers benefitted from recent increases in the product space?

Our main finding is that our utility-based cost-of-living index declines rapidly (approximately 10-15 percent per year). ${ }^{2}$ By any historical standard for innovation, this rate is rarely, if ever, equalled. Second, and perhaps more interesting, our estimates contrast with the rate of change in quality adjusted prices in mainframe computers (approximately 25-30 percent

\footnotetext{
1 Buyer-level data has recently become available. Other studies making use of data from Computer Intelligence Corporations' surveys, which is the source of this paper's data, include Bresnahan and Greenstein [1994], Bresnahan, Greenstein, and Ito [1995], Brown and Greenstein [1995], and Ito [1995]. Brynolfsson and Hitt [1994], and Lichtenberg [1994] use aggregate summaries of this data.

2 We find that weighting by historically later sets of buyers tends to lead to faster rates of decline in our utility-based index, but not enough to alter our basic conclusion. We explain why in the text.
} 
per year), which also declines quite rapidly. The primary reason for these difference is that an overwhelming majority of buyers have inelastic demand. The experience of the majority outweighs the benefits received by a few (with elastic demand), who took advantage of lower prices and extensions in the product space. Third, the distribution of buyer's preferences reveals that most of them could not possibly have placed large value on extensions in the product space. Large price declines induced increases in purchasing, to be sure. However, most buyers initially bought a "small" mainframe system in the early 1980s and still bought a small system at the end of the decade, even with rapidly declining mainframe prices and large extensions in computing capacity.

These results raise several important issues. First, they imply that hedonic methods, such as those used by the U.S. Government for computer price indexes (e.g., see Triplett [1989] for review), may mislead one about the buyer's benefits associated with declines in quality-adjusted prices. When demand is inelastic, as we estimate, then traditional methods may overestimate buyer benefits. This is notable because it contrasts with Trajtenberg's study of CT scanners. Second, our results lead us to speculate that we are observing a new era in mainframe technology. While the rate of technological change has not slowed, we are finding that the few buyers who take advantage of innovation to mainframes are not in the majority. Such an observation contrasts with earlier eras (Greenstein, 1994).

The results in this paper are obtained using a particular functional form - one that allows easy computation. We are aware that our precise estimates depend on that functional form. However, experimentation with a wide variety of specifications for this model yielded slightly different estimates, but not qualitatively different conclusions. We develop these experiments and this analysis more fully in related work (see Brown [1994], and Brown and Greenstein [1995]) and only partly explore the issue here because it detracts from our main points. In this paper we provide extensive description of our data set and a variety of estimates; these exercises provide intuition for why our qualitative conclusions are not sensitive to our specification choice.

This paper adds to a growing literature on the benefits associated with innovation in 
computing. ${ }^{3}$ Some research argues that many buyers did not benefit much either individually or much in the aggregate ${ }^{4}$ or do not benefit without costly adjustments. ${ }^{5}$ Other studies argue that subsets of buyers may have benefitted much over the long run if buyer benefits are calculated with an appropriate model over the right sample of users. ${ }^{6}$ It is not unfair to say that, so far, the empirical evidence about the ultimate economic benefits to buyers still points in many inconsistent directions.

The next section will provide a historical perspective on technological change in mainframe computers. Section 3 will describe the methodology we will follow to arrive at our estimated price index. The fourth section will describe the dataset to be used for this analysis. Our ability to employ our methodology is a result of the detailed dataset we have on the characteristics and behavior of buyers in the mainframe computer market. This type of data has not been analyzed for this purpose previously and allows us to move forward in new directions. The fifth section describes the specific models that we look at and gives the main results of the paper. We compute our utility-based cost-of-living index along with a traditional hedonic index and point out the disparity between the two. In section 6 we give concluding remarks and directions for later research.

\section{Mainframe Computers and Technical Change}

We discuss below our understanding of what buyers do with their systems; this understanding shapes our model of demand, our estimation strategy, and our measure of the benefits from technical change. This discussion also focuses on the impact of technological change in the mainframe computing market in the 1980s. This period witnessed a rapid decline in prices, a dramatic extension of capabilities, and a notable change in the quality of alternatives to

3 For reviews of much of the research results for large systems see Flamm [1987], Dulberger [1989], Gordon [1989], Triplett [1989], Berndt and Griliches [1993], Griliches [1994], for example.

4 For variations on this theme, see Loveman [1994], Berndt and Morrison [1992], Bailey et al [1992], and Sichel and Oliner [1994].

5 See Bresnahan and Greenstein [1994] or Bresnahan and Saloner [1994] for studies suggesting that the costs of adjustment are highest to those who could potentially benefit the most from new technology.

6 See Brynolfsson and Hitt [1994], Bresnahan [1987], Hendel [1994], Brynolfsson [1 993], Lichtenberg [1994], Greenstein [1994]. 
mainframes.

Prices declined steadily and pervasively across all systems, as measured by prices per CPU speed and memory capacity. ${ }^{7}$ The maximum feasible system capacity, as measured by maximum computing memory and CPU speeds, also expanded rapidly. ${ }^{8}$ This permitted users to address increasingly more complex problems involving more calculations and large data bases, and regularly perform tasks that could not be previously accomplished, let alone attempted. ${ }^{9}$ This change had many antecedents in the previous two decades, so it should not have caught any buyers by surprise. ${ }^{10}$

Broadly speaking, by the 1980 s users had come to expect change -- i.e., lower prices, extensions of capabilities, or entirely new products -- and plan for it. In response, buyers modified the memory and speed of their CPU, but kept other durable investments in software or peripherals. Or, buyers enhanced particular software programs or peripheral components, but not other parts of their systems. A regular pattern emerged in the mid 1960s and 1970s and continued into the 1980s: peripheral and software upgrading induced bottlenecks in CPUs, which later induced further CPU upgrading, which later induced further peripheral and software enhancements, and so on. This pattern was well-known and widely studied. ${ }^{11}$

An important point follows from this pattern: upgrading to larger CPU capacity became associated with taking advantage of technical improvements in software and peripherals and so on. Thus, for many buyers, demand for greater computing capacity proxies for the demand for new peripherals and improvements in software, reflecting the demand for new goods and services

7 See Dulberger [1989], Gordon [1990], Triplett [1989]. Similar estimates have been found for peripheral and selective software programs. See Cole et al [1986]. Our results below show a decline of over $25 \%$ a year.

8 For example, our data in this paper shows an expansion in product space from a maximum of 20 MIPS to 110 MIPS in under 5 years.

9 Probably the commercially most important developments were associated with "on-line-transaction-processing" (OLTP) applications, i.e., applications that required multiple-users to simultaneously access and update large databases. A wide series of innovations, dating to the late 1970 s and early 1980 s, to hardware architecture, operating system design, networking technology, and application software enabled and improved OLTP applications (Freedman and Cornford [1991]). Many large users, insurance and banking users, wholesalers, and many large data-base users employed these developments in new inventory and reservation systems.

10 For examination of the diffusion of computing systems and some of its economic determinants during this time period, see Greenstein [1993], [1994] or Bresnahan and Greenstein [1994].

11 For models of organization use and pricing of computer systems, see Inmon [1985] or Mendelson [1985] 
This is a useful interpretation since the demand for computing capacity is easily observable at a user level, but the demand for new goods and services is not.

Several contrasting forces influenced the benefits buyers received from new computing systems. First, because new goods and services resulted from the interaction of improvements in peripheral components, software, and CPUs, the economic value created by the purchase of computing capacity did not necessarily relate in any linear fashion to the decline in prices of constant quality CPUs. It may be faster if declines in prices enabled a user to realize local economies of scale in the distribution of computing services and employment of computing capital investments. ${ }^{12}$ For example, in many on-line transaction processing applications buyers value a larger computing capacity (embodied in CPU), because it allows more users, faster response times with larger databases. Many researchers of centralized management of computing facilities (e.g., Inmon [1985] ) emphasize this notion.

In contrast, however, another line of research emphasizes that many buyers may not have realize localized economies of scale in their large systems in this period (Friedman and Cornford [1989]). These researchers of centralized management of computing facilities emphasize increasing buyer dissatisfaction with translating enterprise needs into feasible technical solutions in the 1980s. The complaints centered on problems inherent in centralized management (of mainframes) rather than technology alone, and hence, no pure "technology fix" was possible. In this view, the bottlenecks inherent in centralized management potentially choked off much advance, particularly in the 1980 s.

Finally, development in the market for minicomputers, workstations, and personal computers influenced mainframe demand, and thus, the benefits from innovation to mainframes. First, by the mid 1980s minicomputer vendors offered users viable growth paths for their systems if the users' needs outgrew large superminis. Small users or divisions within large corporations found them attractive as a means to avoid centralized mainframe management. Second, by the mid to late 1980s, even smaller platforms, associated with personal computers and workstations, offered a different type of decentralized platform for small computing jobs involving small

12 Localized economies could produce a "repackaging problem" in CPU product characteristics, i.e., a single mainframe may not be equivalent to, but superior to, two mainframe computers embodying one-half the characteristics. 
partitionable data-bases, word-processing, and spreadsheets. Some buyers could (and many did) break up their computing needs into smaller units, taking advantage of the advantages of smaller platforms. ${ }^{13}$

How do the trends in the minicomputer, workstation, and microcomputer market influence a study of mainframes? First, not many new buyers were drawn into the mainframe market in the 1980s. The majority were experienced buyers with their legacy systems. This stable set of mainframe buyers was identified and surveyed each year, which provides us with very detailed data on their behavior. ${ }^{14}$ Second, the purchase of the very smallest systems is outside the view provided by the data used here. Hence, we need an measurement strategy that does not rely on observing the choice of the "outside good." Third, until the very late 1980s it was not obvious whether mainframe buyer behavior would change, if at all. While earlier generations of buyers had taken advantage of innovation, could the same be said of the late 1980s? It was no longer obvious that this group of users was ready or willing to adopt new generations of higher capacity machines pushing out the technical frontier.

In sum, technological change was more than a simple fall in the price level. The willingness to take advantage of new capabilities became associated with a willingness to adopt computing capacity of higher levels. The willingness to pay for new capacity, whether new capacity was valued or not, determined the value to buyers from innovation in computing Measuring the extent of these benefits is ultimately an empirical issue.

\section{Methodology}

We employ an approach for measuring the value of innovation to buyers based on Rosen [1974], which, to our knowledge, has never been adapted to estimating buyer benefits from technical change. This methodology has the advantage that it measures the demand for speed and

13 If a buyer does not have a "repackaging" problem -- due to the absence of many investment in complementary components, which is a big "if" -- declines in prices may simply induce purchases of cheaper computing power, but not necessarily purchases of a bigger CPU in a mainframe. That is, the choice between a large or a small CPU then may depend solely on the relative price/per characteristic for small and large systems, as each is introduced.

14 There was limited exit from the market by certain types of users. Scientific and engineering users had traditionally been the first to take advantage of faster computing speeds and larger memories, but this was beginning to be less true by the late 1980s. See Bresnahan and Greenstein [1994] 
memory and other characteristics directly tied to the buyer's demand for computing capacity to handle large data bases, greater functionality, more users, and better software. Moreover, this econometric model is easily modified to formally suit simultaneous decline in price per characteristic and expansion of product space, as we show below. Third, this method's econometric strengths and weaknesses are well known, which was extremely helpful in implementing the model. ${ }^{\text {is }}$ Finally, it is well suited for measuring the effects of the distribution of demand across the product space, which is an important issue in this market. We continue in the next section to review Rosen [1974] and to discuss the issues surrounding his proposed methodology.

Our study follows in the spirit of Trajtenberg [1990], who pioneered the estimation of buyer benefits with his study of buyers of CT scanners. ${ }^{16}$ We chose not to initially follow the procedure described by Trajtenberg, and instead extend an alternative based on Rosen. We will explore Trajtenberg's approach in further work. ${ }^{17}$

\subsection{A Model of Buyer Benefits from Innovation}

Rosen [1974] suggested a model and methodology for thinking about the demand and supply in a differentiated product market. Rosen posits that a characteristic/price surface represents a locus of equilibrium transactions between buyers and sellers. This surface represents an upper envelope of buyers' bid functions and a lower envelope of sellers' offer functions (see Figure 3.1). Transactions occur where these bid and offer curves are tangent. As a consequence, the marginal price function represents the locus of intersections between buyers' marginal bid and sellers' marginal offer curves (see Figure 3.2). Rosen suggested the following system of equations

15 For example, we were able to leam from the experiences of Rosen (1974), Brown \& Rosen (1982), Diamond \& Smith (1985), Bartik (1987) and Epple (1987), and avoid some subtle econometric pitfalls.

16 Also see Bresnahan [1987], who used a model of the derived demand for computing in the banking sector to measure the improvements to banking users from improvernents in computing.

17 Trajtenberg faced the problem of upward sloping demand curves, which he had to solve with an ad-hoc solution based on hedonic price functions. He argued that this came as a result of a correlation between unobserved quality characteristics and price. It is now understood that in a logit setting, this problem has no solution without explicit modeling of the random error (see Berry, Levinsohn \& Pakes 1993), which may be cumbersome to apply. We anticipate these problems, as well as other issues associated with specifying an appropriate "nesting" of preferences when the choice set is large, as it is here. Hence, it is easier to begin with Rosen. Also see the discussion in Berndt (1991). 
described the market:

$$
\begin{aligned}
& p_{j}(x)=E^{j}\left(x_{1}, \ldots, x_{n}, Y_{1}\right) \quad \text { Demand } \\
& p_{j}(x)=G^{j}\left(x_{1}, \ldots, x_{n}, Y_{2}\right) \quad \text { Supply. }
\end{aligned}
$$

Here, $p_{j}$ represents the estimated marginal price for characteristic $j$, defined as the first derivative of the price function at the observed levels of characteristics, and $x_{j}$ represents the observed levels of characteristics (e.g., speed, memory, and other features of a computer system). Because of the potential nonlinearity of the price surface, seen in Figure 3.1, buyers and suppliers simultaneously choose both the levels of characteristics and the marginal prices for those characteristics (given by the slope of the surface). This implies that the system given by (3.2) has $2 n$ equations and $2 n$ endogenous variables (where $n$ represents the number of characteristics). $Y_{1}$ and $Y_{2}$ represent exogenous demand and supply shift variables. These are simply characteristics of corresponding buyers and suppliers.

To fix ideas, we now describe this model more formally for the case where the buyer purchases only one system and the price/quality surface is exogenous to the buyer, which is the situation corresponding to our data. For simplicity, this model assumes that the demand function is the same over time, but that the price/quality surface changes due to changes in supply conditions. This demand assumption can be relaxed somewhat in practice, subject to practical econometric constraints described below.

In any given year, this model is similar to a consumer's utility maximization problem. Here we have a buyer solving the problem:

$$
\max u(x, P) \text { st. } P=H_{t}(x)
$$

where $u$ represents the buyer's utility from purchasing characteristics $x$ for price $P, H_{t}$ is the hedonic price function at time $t, x$ is a vector of product characteristics and $P$ is the product price. 
Up until some maximum, $H$ is assumed to be twice continuously differentiable with $\mathrm{d} H / \mathrm{d} x>0$. $u$ is chosen such that $u_{x}>0, u_{x x}<0$ and $u_{p}<0$, when the buyer is at an interior solution. At a "corner" solution, the buyer may be at either the minimum (i.e., near zero) or the maximum characteristics available (i.e., which changes over time). Solving this problem yields a solution $\left(x_{t}^{0}, P_{t}^{0}\right)$. For simplicity, we later assume that $u$ is additively separable in characteristics, although this can be relaxed.

This model is well suited to measuring buyer valuation from innovation because it gives us the "hypothetical price change that would have resulted in the same welfare effect" as innovation (Trajtenberg [1990], p 31). We then aggregate each buyer's benefits into a market wide "cost-of-living" price index. ${ }^{18}$ Let us summarize the entire procedure. The hypothetical price index is computed by taking the buyers in each year, $t$, and placing them into consecutive earlier or later years, $t+1, \ldots, T$, to determine the set of characteristics they would have purchased had they actually faced a another year's set of choices, as represented by that year's price function, which presumably differs from other years. The new set of characteristics is computed by finding the point at which each buyer's demand curve intersects the marginal price functions for the other year. We then compute the price that this new set of characteristics would have cost in year $t+k$, a "counterfactual price." We then compute the price that this set of characteristics would have cost in year $t$, a "constant-utility price." The ratio of these two prices, the constant-utility price and the counter-factual price, is the index for this buyer's benefit from innovation. This is depicted in Figure 3.3 for a single individual and a single computer characteristic

More formally, for interior solutions, the first order condition for (3.4),

$$
\nabla u\left(x, H_{t}(x)\right)=0
$$

implies an optimal choice for $x$ at time $t$, which we will call $x_{t}^{0}$. Given this, we define $P_{t}^{0}=H_{t}\left(x_{t}^{0}\right)$

18 The estimation and construction of cost of living indexes in differentiated product markets has many antecedents. In addition to Trajtenberg's application and discussion, see related analysis by Deiwart [1976], Feenstra [1993], [1995], Fisher and Shell [1972], and Fisher and Griliches [1995] 
and $\mathrm{u}^{0}=u\left(x_{t}^{0}, P_{t}^{0}\right)$. In words, $P_{t}^{0}$ is the observed price the buyer paid for the observed set of characteristics at time $t$, and $u^{0}$ is the level of utility the buyer achieved at time $t$. Using (3.5), but substituting $H_{t+k}(x)$ for $H_{t}(x)$, we obtain an optimal solution for $x$ at time $t+k$, which we call $\hat{x}_{t+k}$. We then define $\hat{P}_{t+k}=H_{t+k}\left(\hat{x}_{t}+k\right)$ and $\hat{u}_{t+k}=u\left(\hat{x}_{t+k}, \hat{P}_{t+k}\right) . \hat{P}_{t+k}$ is the counter-factual price the buyer would pay for the counter-factual set of characteristics when facing the pricing surface at time $t+k$, and $\hat{u}$ is the level of utility the buyer would achieve at time $t+k$. Finally, we define $P_{t+k}^{*}$ as the $P$ that satisfies $u\left(\hat{x}_{t+k}, P\right)=u^{0} . P_{t+k}^{*}$ is the constant-utility price the buyer would pay to purchase the counter-factual set of characteristics while remaining at the level of utility observed at time $t$.

To compute an index for a single buyer, we need to know the level of characteristics that would have been purchased had the buyer actually faced $\mathrm{H}_{t+k}$ rather than $\mathrm{H}_{t}$ as shown in Figure 3.3. This is given by $\hat{x}_{t+k}$ defined above. At time $t+k$ this bundle of characteristics will cost $\hat{P_{t+k}}$ and the buyer will achieve a level of $u$ equal to $\hat{u}_{t+k}$. Next, we determine the counterfactual price $\hat{x}_{t+k}$ would have cost the buyer had $\hat{x}_{t+k}$ been purchased instead of $x_{t}^{0}$ in year $t$ holding the buyer on the same bid curve, $u^{0}$. We need to find the price of $\hat{x}_{t+k}$ on the bid curve of the observed year, $\mathrm{u}^{0}{ }^{19}$ This is $P_{i+\mathrm{k}}^{*}$ defined above and shown in Figure 3.3. ${ }^{20}$

\footnotetext{
19 The reason that we can hold $\hat{x}_{t+k}$ constant when moving from time $t+k$ back to time $t$ is a consequence
} of the assumption that demand functions remains the same over time. We actually shift $\mathrm{H}_{r+k}$ vertically until it is tangent to $u^{0}$. When we shift $H_{t+k}$ parallel, it will be tangent to $u^{0}$ at the same $x$ that it was tangent to $\hat{u}_{t+k}$, namely $\hat{x}_{t+k}$ 
The procedure easily generalizes to a buyer that hits a "corner." As a practical matter, there are two potential corner solutions in our counter-factual levels of characteristics. We illustrate both in Figure 3.4 for a backward index. First, a buyer may choose a counter-factual set of characteristics which is larger than the largest system that was available at time $t-k$. In figure 3.4 , this buyer begins at $u^{0}$ in time $t$ and would prefer to purchase another large system, call it $u^{1}$, even at higher prices. However, $\hat{x}_{1, t-k}$ is outside the range of available products. Had the range of available products been larger, the buyer would have received benefits of $\hat{u}_{1, t-k}$. When the buyer is constrained to purchase lower than optimal capacity, we give the buyer the utility $u *_{1, t-k}$, associated with largest set of characteristics which was available at time $t-k$. A similar analysis holds for the case of a buyer looking forward from time t to time $t+k$. Second, depending on the slope and location of the demand curve, it is possible that a buyer (looking back) would no longer be in this market, but would instead be in a market for some smaller computer, say a minicomputer. In this case, we compute the utility level which would leave the buyer indifferent between being in the mainframe market and some outside good. This utility level occurs where $H_{t-k}$ and $\hat{u}$ are at zero characteristics, which we represent as $u *_{3, t-k}$, If overall prices are always declining over time and demand curves are well-behaved, this second corner does not generally arise in a forward index.

The counterfactual price is a function of two factors. The first important factor is a buyer's elasticity of demand. If a buyer's marginal utility in system capacity diminishes rapidly, then declines in price per unit of capacity will not induce large changes in expenditure. Second is whether buyers are constrained by the available product space. That is, if a buyer has an elastic demand for more capacity, a price decline may induce a large increase in desired capacity,

20 Unfortunately, the bid curve $u^{0}$ is unobserved. All we know is the observed price $P_{\imath}^{0}$. However, the demand curve (3.5) is actually an estimate of the slope of the marginal bid curve, $u^{0}$. Therefore, we integrate the demand function between $x_{t}^{0}$ and $P_{i+k}^{*}$. If we then add $P_{i}^{0}$ to this amount, this gives us the price we are looking for $-P_{i+k^{*}}^{*}$ 
potentially outside the range of available products. If the buyer is constrained by limits in the available product space, this too will influence the counterfactual price and the associated benefits from innovation

Formally, to compute a price index for innovation, we set the base year for our index to the year the buyer is observed. If $t$ is the year we observe the buyer, indexed by $i$, then

$$
\frac{I_{t+k}}{I_{t}}=\frac{P_{i t+k}^{*}-\hat{P}_{i t+k}}{P_{i t+k}^{*}}
$$

where $t$ represents the observation year and $t+k$ some later year, and $\mathrm{I}_{t}$ represents the price index for year $t$. We compute this index for each buyer, $\mathrm{i}$, observed in year $t$. A similar computation holds for $\mathrm{t}-\mathrm{k}$, as shown below.

The final step is to aggregate these individual indexes into a single index. For a forward index we create a weighted average of these individual indexes, using either $P_{t}^{0}$ or $P_{t+k}^{*}$ as the weights. Thus, we compute both

$$
\begin{gathered}
1-\frac{\sum_{i} P_{i t}^{0} \frac{P_{i t+k}^{*}-\hat{P}_{i t+k}}{P_{i t+k}^{*}}}{\Sigma_{i} P_{i t}^{0}} \text {, and } \\
1-\frac{\sum_{i} P_{i t+k}^{*} \frac{P_{i t+k}^{*}-\hat{P_{i t+k}}}{P_{i t+k}^{*}}}{\sum_{i} P_{i t+k}^{*}}
\end{gathered}
$$




$$
=\frac{\Sigma_{1} \hat{P}_{i t+k}}{\Sigma_{1} \hat{P}_{i t+k}^{*}}
$$

which we call the "forward index."21 These choices of weights allow the index to account for the distribution of buyers across the product space. Notice that the second one also represents a ratio of surplus to expenditure. It turns out that with our data, the difference between using $P_{t}^{0}$ and $P_{t+k}^{*}$ as weights is minimal. We compute an index of this type for each year $t$ from $t=1$ through $t$ $=T-1$ with year $T$ as 100 in each index. Doing this allows us to examine how the index changes as the distribution of buyers changes. ${ }^{22}$

In an analogous fashion, we can measure the benefits received from buyers in year $t$ when given the alternative choice set at time $t-k . P_{t}^{0}$ is still defined as the observed price for the observed set of characteristics, and $\hat{P}_{t-k}$ is still defined as the counter-factual price for the counter-factual set of characteristics. $\quad P_{t-k}^{\bullet \bullet}$ will now be defined as the price that solves $u\left(x_{t}^{0}, P\right)=\hat{u}$, or the price that the buyer would pay to purchase the observed set of characteristics while remaining on the counter-factual bid curve. The index for an individual buyer, using $P_{t}^{0}$ as the weight, is computed as

21 For a similar derivation see Fisher and Griliches [1995].

22 Note that in computing this index we have compared utility levels at the counterfactual level of characteristics. Since our bid curve is concave, if we compared utility levels at the observed level of characteristics we might be confronted with an undefined counterfactual price. We avoid this problem by restricting our attention to the counterfactual level of characteristics. Trajtenberg [1990] also faced this problem in his formulation and chose not to define an index for this case as a result. 


$$
\begin{gathered}
1+\frac{\Sigma_{1} P_{i t}^{0} \frac{P_{1 t-k}^{* *}-P_{1 t}^{0}}{P_{1 t}^{0}}}{\Sigma_{1} P_{1 t}^{0}} \\
=\frac{\Sigma_{1} P_{i t-k}^{* 0}}{\Sigma_{1} P_{i t}^{0}}
\end{gathered}
$$

We will call the index computed in this fashion the "reverse index." Again, this index is a ratio of surplus to expenditure.

The forward and reverse indexes are similar to welfare computations and price index computations common to economics. The index for the individual buyer answers the question: How much money would one have to give a buyer in 1985 to make him indifferent between the system he has in 1985 and the optimal system he could buy in some later year? This is similar to an equivalent variation computation. The weighted market index uses the expenditures by buyers in some base year, say 1985, and then uses later year expenditures to determine the price change. This is similar in computation to a Laspeyres price index since we are using previous year quantities as our base. By a similar argument, the reverse index is analogous to a compensating variation computation and a Paasche price index. We do not expect the forward and backward indexes to differ much, either moving forward from time $t$ to time $t+k$ or backward from time $t+$ $k$ to time $t$, unless the distribution of buyers changes radically between the two time periods. ${ }^{23}$

\subsection{Estimating Demand}

Following the suggestions of Brown and Rosen [1982] and Diamond and Smith [1985] we make these initial assumptions: First, we assume that each buyer chooses only one system. This is

23 We compare the different properties of our forward and backward indexes in Brown and Greenstein [1995]. 
not implausible for the mainframe market. Most "sites," which we define below, make only one acquisition in a year, if any. ${ }^{24}$ Second, we assume the demand parameters are the same for all buyers and do not change over time. Each buyer's demand is differentiated only by a set of buyer characteristics used to describe the heterogeneity among buyers. While it is possible to relax this somewhat in the context of our experiment, such a relaxation unnecessarily complicates the econometrics and the reporting of results and adds little to our main point, as we explain below. Third, we assume that supply is exogenous to buyers and that demand can be estimated without estimating supply. This implies buyers take the hedonic price function as exogenous and simply locate themselves on it. We discuss tradeoffs associated these assumptions below after discussing estimation issues.

We begin by estimating a hedonic price function for each year which is exogenous to each buyer. These functions may take a general form

$$
g_{t}\left(P_{k t}, x_{k t 1}, \ldots, x_{k t n}, e_{1 t}\right)=0 \quad t=1, \ldots, \mathrm{T}
$$

where $x_{k j j}$ represents the $j^{\text {th }}$ computer characteristic of product $\mathrm{k}$ available in year $\mathrm{t}$ and $g$ is some functions which may change over time. $e$ represents the error term. We estimate (3.8)

separately for each year. ${ }^{25}$

The next step is to differentiate (3.8) with respect to each of the $x_{j}^{\prime}$ s to obtain $n$ marginal price functions for each year. Each of these functions is a function of the $n$ computer characteristics. Denote these functions by $m p_{i j p}$ for buyer $\mathrm{i}$, characteristic $\mathrm{j}$ and time $\mathrm{t}$. With these $m p_{i j t}$ functions we compute estimated marginal prices for the characteristics by evaluating the $m p_{i j t}$ at the observed levels of characteristics to obtain $m \hat{p}_{1 f t}$. This yields $n$ vectors of estimated

24 A number of different issues arise when buyers purchase multiple systems within an observable time period. For different treatments, see Hendel [1994] or Ito [1995]. Hendel estimates the determinants of the acquisition and holding of multiple micro-computers from multiple vendors and applies the estimates to measuring buyer benefits from innovation. Ito estimates a dynamic model of mainframe investment and mainframe stock growth in order to determine the relative importance of sunk costs.

25 As stated earlier, $g$ is usually taken to be logarithmic. However, we will not attempt to use this form in the computation of our utility index because of the computational difficulties that will arise in attempting to solve a system of nonlinear equations. 
marginal prices for each year. We combine these vectors to obtain a marginal price vector for each characteristic.

The next step is to estimate demand, which may take a general form of

$$
m \hat{p}_{i j}=f\left(x_{1 i}, \ldots, x_{n i}, B_{1}, v_{i}\right),
$$

where $v_{i}$, is an error term. Because in general the $x_{i j}$ in (3.9) are correlated with $v_{i}$, we must provide instrumental variables for the estimation of (3.9) (Epple [1987], Bartik [1987]). Plausible instruments, as described by Bartik [1987], should be correlated with the choice of computer characteristics but uncorrelated with unobserved tastes. $B$ represents buyer characteristics and describes the heterogeneity among buyers. While the model determines the shape of each individual demand curve, the $B$ of (3.9) will shift the demand curves.

At this point a number of identification issues arise. Recall that in the first step we estimated (3.8) separately for each year $t$. Brown and Rosen [1982] pointed out that if (3.8) were estimated as a pooled regression with all years included, estimation of (3.9) may not yield any new information since it is a function of the same $\boldsymbol{n}$ characteristics. For example, if (3.8) were quadratic and (3.9) linear, then the marginal price functions, $m p_{i j}$, would be linear functions of the $x_{j}$. Thus, since (3.9) is also linear and a function of the same $n$ characteristics, there would be nothing to estimate. The coefficients in (3.9) could be determined directly from the coefficients in (3.8). Brown and Rosen suggested that one way around this without imposing any functional form restrictions would be to estimate (3.8) separately for each market (here distinguished by time). This would result in a different marginal price function for each year and, assuming the demand function was constant over time, a meaningful estimate in (3.9). Of course there needs to be a significant difference between the estimates in (3.8) for this to hold true. This suggestion was reiterated by Diamond and Smith [1985] and employed by Bartik [1987].

Now the trade-offs inherent in our assumptions should be apparent. To identify demand parameters we assume throughout that demand functions remain constant over time. This is less disturbing an assumption than it might first appear to be. First, relaxing this assumption 
unnecessarily complicates the econometrics and reporting extra results does not add anything germane to our analysis. ${ }^{26}$ Second, the mid to late 80 s is a mature stage of the mainframe computer industry. It is not difficult to argue that buyers know how important computing speed is relative to memory, and the relative valuation of the two in use does not vary during the period. We would be more uncomfortable with this assumption if the time period stretched for much longer than seven years or was during a period of turbulent change and growth in the industry, such as the late 1960 s.

Another assumption concerns estimating supply. We will assume supply is exogenous to buyers. Diamond and Smith [1985] argue that either side of the market can be estimated without regard to the other side. Diamond and Smith argued that this was reasonable since the source of simultaneity in this model does not arise, for example, between a buyer and a computer system. Instead, movements by buyers are to new systems rather than along the offer curve of the same system. ${ }^{27}$ However, this is an industry dominated by large firms, and it is possible that they influence the shape and location of the price surface. This would then imply that changes we see in a computed index are not necessarily attributable to technological change but instead to a combination of technological change and changing firm market power. Since our goal is to measure the benefits that accrue to buyers from facing different choice sets, this potential confusion should have little affect on our results. Just to be sure, we compute separate results for IBM and non-IBM buyers. We would be disturbed if the two indexes were markedly different. If we later incorporate supplier behavior, as we hope to do later, we will consider alternatives.

\section{Data}

This study's data is at the buyer level and describes the acquisitions as well as information about the buyers making the acquisitions. ${ }^{28}$ Previous work had data on the available systems,

26 As explained above, to identify the model the number of consecutive years with the same demand function must exceed the number of dimensions of the product space. For example, with a single characteristic, we could estimate models formed by assuming that two consecutive years had the same demand function. With three characteristics, as in our largest model, we need four consecutive years. While we could certainly do this, reporting all these results requires many tables and adds little additional insight.

27 This follows from the typical assumption that each supplier produces only one product and each buyer purchases only one. We assume that there exists an offer curve for each system rather than each supplier. 
their characteristics and their prices. Because of the differences in the data, we are able to address the question of the amount of technological change taking place in a different manner.

The data to be used for this analysis is a subset of the Computer Installation Data File kept by the Computer Intelligence Corporation (CIC). All information on the file is collected directly from the users through mail surveys and telephone follow-ups and it is updated on a continuous basis. CIC prepared a database containing their complete records for every site in the United States with a medium to large general purpose computer system for every year from 1984 to 1991. This time period was selected because CIC could guarantee the data's historical accuracy and completeness. Each Computer Installation Data File record contains both site data and system data. ${ }^{29}$

This particular subset of CICs data files is extraordinarily rich in detail. CIC provides data on over 44,000 medium to large systems in 1984 and over 58,000 by 1991 . Each year provides data on over 14,000 sites that use a medium to large computer system. Each of those 14,000 records includes the name and address of the private company (and parent) at which the system is located, as well as broad information about the company, such as the (four digit) SIC associated with the site, the number of employees and the amount of revenue. ${ }^{30}$

Since our interest here is the effect of new technology on price index computation, we look only at the acquisitions of new computer systems. This is similar to the previous research where researchers typically use the set of systems available for sale to perform their analysis. The acquisitions data set was generated from the site data, which included a variable for each system indicating whether it was a new acquisition or not. ${ }^{31}$ In order to perform our analysis we require

28 The buyers are private firms, educational institutions and government organizations.

29 Site data refers to those data elements concerning the company at which a computer system is located. "System" is used as a collective term rather than meaning a computer system itself. System data includes data on the mainframe, software and peripheral equipment at the computer installation.

30 Other information includes the system name and model, the amount of memory, the amount of peripheral equipment used, the primary language used, the likely market value of the system, the method by which the system was acquired and at what level such acquisition decisions are made. The file also provides information about the total MIPS and DASD, as well as the number of programmers at the site. Unfortunately, some of the variables are not reported for the entire time period, making it a difficult task to use these fields.

31 We actually checked two consecutive years of data. Many sites are surveyed on an annual basis, but often in the middle of the year. Hence, any acquisitions late in the year are not yet recorded in the end-of-year sample if the site has not recently been surveyed. This sampling frame unavoidably produced a smaller number of acquisition in 
data on the site from the previous year. Therefore, we removed all observations for which there was no site information the previous year.

To complete the dataset we consulted CIC's Computer Systems Report Users Guide, which contains information on all systems known to them. The Guide contains the system name and a list of characteristics including MIPS, minimum memory, maximum memory, KVA (kilovolt-amperes) ratings and others. We matched the system names with those in the Guide and merged the characteristics with the list of acquisitions. Due to name discrepancies and the inclusion of some non-mainframe acquisitions in the dataset, the size of the data was narrowed to 21,268 acquisitions at unique sites in unique years. This is the dataset used in the analysis. In the remainder of this section we give definitions for the different variables used, as well as descriptive statistics. More detailed descriptive statistics can be found in the Appendix of Brown [1994].

\subsection{Price}

The system price we use here is proved by CIC and is defined as the "estimated value of a 'typical' configuration if purchased today." The drawback to this is that all acquisitions of the same system will get the same price association with them regardless of the true configuration which was purchased. "Typical" is defined by CIC as "an average size system with a normal compliment of peripherals and terminals." This is the same type of price that previous work has used. The computer characteristics to be described later are associated with systems in the same manner, so that all systems of the same type have the same price and the same characteristics during a given year. Fortunately, prices for the same system change over time, so there is variation in both the cross section and time series. While this is not the most desirable setup, it is consistent, and is virtually the same as what has been used in the hedonic literature.

We transformed the price data by adjusting for inflation using the Producer Price Index. This was done so that we would be measuring technological change with inflation factored out. Table 4.1 provides descriptive statistics for the transformed price data (measured in hundreds of dollars).

the data set for 1991 


\subsection{Computer Characteristics}

The mainframe characteristics we choose to use are minimum memory, maximum memory and MIPS. Minimum and maximum memory are the minimum and maximum amounts of main storage supported on the system. MIPS is a measure of the speed of the mainframe measured in millions of instructions per second.

Main memory is valued for its storage use to allow for quicker access to software and data. Its measurement in bytes is standard in the industry so that different systems' memory may be compared in a straightforward manner. Most previous studies have often used both the minimum and maximum memory. This was done either to account for the lack of information as to which size of memory went with the recorded price, or to avoid the influence of different pricing schemes for the low-end models when different prices are available for different memory sizes (see Triplett [1989] and Dulberger [1989]). For a description of the 'pricing schemes' see Phister [1979]. We use both minimum and maximum memory because we do not possess a price for different memory configurations for each system. Tables 4.2 and 4.3 give descriptive statistics for minimum and maximum memory.

MIPS is the best measure of speed for our purposes, though considerable previous debate influenced this choice. No less than five measures of speed, including addition time, multiplication time, memory cycle time, MIPS and KOPS (thousands of instructions per second) have been introduced as independent variables in the specification of the hedonic function. For definitions of these measures and others see Triplett [1989]. The most recent studies prefer to use MIPS because it combines the speeds of many instructions and weights each instruction by the relative frequency of that instruction in the job. If the job is representative of the jobs which will be performed by the system, then this weighted measure computes some sort of "expected" speed. However, since typical jobs vary widely across processors, comparability across processors is difficult (see Triplett). For this reason, Dulberger [1989] chose to exclude all data except IBM and plug-compatible processors for which equivalent MIPS measures were available. Triplett's reply to this choice is that "...a non-comparability that may be disastrous for machine selection purposes may yet be acceptable for an economic measurement, in that the measurement error may be randomly distributed around the true hedonic regression line" (Triplett p.149). We choose to 
include all acquisitions, not discriminating on the basis of comparable MIPS. Later, for comparison purposes, we will perform the same exercise using only IBM and PCM processors. Table 4.4 provides descriptive statistics for MIPS.

Another variable we feel is important is reliability. Unfortunately, it is not clear how one would go about measuring this. However, in this era, the technology is more mature than in previous eras and reliability is probably not changing much over time or across systems. This would not necessarily be the case if we were comparing 1970 systems with 1990 systems. We would also like information on input/output capabilities, which is very important to mainframe performance. Since this feature positively correlates with MIPS, we expect to attribute much of its value to MIPS. ${ }^{32}$

\subsection{Buyer Characteristics}

The buyer characteristics are the variables which describe the heterogeneity among buyers. We chose seven categories of variables which were either available, or could be generated, from the CIC data. Each of the variables is lagged one period similar to the procedure followed in Greenstein [1992] and Bresnahan and Greenstein [1994]. These variables include dummy variables for various SIC groupings, a dummy variable for whether or not the site owned an IBM system, the estimated purchase value of installed systems at the site, the MIPS rating of the system at the site with the largest MIPS rating, the total MIPS for all installed systems at the site, the total KVA rating for all installed systems at the site and the technical age of the youngest system owned during the previous year. Tables 4.5 and 4.6-4.12 give definitions and descriptive statistics for the buyer characteristics.

\subsection{Instrumental Variables}

Because in general the $x^{\prime}$ s in the demand estimation are correlated with the error term in

32 Berndt (1991) generally discusses the problem of omitted variables in hedonic estimates. He points out that if reliability is correlated with the producer, then a producer dummy variable might be appropriate. While this may be true, there may be other unobservable characteristics which may be correlated with the producing firm which are not valued by buyers, but which in fact would affect our index. For this reason we chose not to include firm dummy variables. For a list of variables used in previous research see Triplett (1989). 
that equation (Bartik [1987], Epple [1987]), we need to estimate that equation by instrumental variables. The instruments should be variables which affect the choice of characteristics but do not affect unobserved tastes. The variables we use are time dummy variables, region dummy variables, an SMSA dummy variable and characteristics of the closest systems in characteristics space as measured by the Mahalanobis distance between systems. This distance is defined as

$$
\left(x_{0}-x_{1}\right)^{T} \Sigma^{-1}\left(x_{0}-x_{1}\right)
$$

where $x_{0}$ represents the characteristics of the system, $x_{\mathrm{i}}$ represents the characteristics of all systems except $x_{0}$ and $\sum$ represents the covariance matrix of the variables minimum memory, maximum memory and MIPS. ${ }^{33}$ Each of these variables affects the marginal prices paid for computer characteristics. Assuming that tastes do not change over time or across regions and that tastes are unaffected by whether or not the buyer resides in an SMSA, these variables are uncorrelated with buyers' tastes, making them appropriate instruments. Definitions of these variables are given in Table 4.13.

\section{Results}

In this section we will compute a variety of utility-based cost-of-living indexes on methods we have proposed in the previous sections. Two main themes will emerge. First, it will be shown that constant-quality price indexes overstate the true benefits buyers receive from improvements in technology. This will be seen by the fact that our utility index, which assumes a declining marginal utility for characteristics, has a lower growth rate than the hedonic index. Second, it will be shown that this rate is mildly sensitive to the distribution of buyers across the product space. However, even though the utility index is sensitive to this distribution, all estimates will yield a similar conclusion - that most buyers do not value extensions in the product space.

33 The idea is that neighboring systems provide information about the shifts in costs of production without correlating much with buyer demand. A related idea may be found in Berry [1993]. 


\subsection{One Characteristic Model}

We begin by looking at a model with one characteristic. This is a variation of a model used by Witte, Sumka and Erekson [1979] and analyzed by Epple [1987]. We choose this model because of its ease of computation, because it establishes basic intuition for the multivariate case, and it is much easier to explain.

We first estimate a hedonic surface for each year of the form

$$
P_{i t}=\beta_{0 t}+\beta_{1} M I P S_{i t}+\beta_{2} M I P S_{i t}^{2}+u_{i t}
$$

where $P$ is the price of the system and MIPS represents the MIPS rating of the system. ${ }^{34}$ Table 5.1 gives the estimation results and Figure 5.1 show the graphs of these hedonic surfaces. From the figure we notice that the shapes of the surfaces are not constant over time. First notice that the product space expands over time, as anticipated. Second, the 1986 surface crosses the 1985 surface. This implies a technological retrogression (in terms of price per performance) from 1985 to 1986 for part of the product space. This retrogression implies that an index may rise between 1985 and 1986 before beginning to decline through the end of the sample. Finally, our estimation results show that all coefficients are significant except the intercept terms in 1986 and 1991 and that the parameter estimates vary widely over time. This variation is important because it implies that a flexible functional form is more appropriate than estimating a hedonic surface which only allows the intercept to change, as has been done in the past. ${ }^{35}$

The next step is to differentiate (5.1) with respect to MIPS to obtain the marginal hedonic surface. This is given by

$$
m p_{m i p s, i t}=\hat{\beta} 1 t+2 \hat{\beta}_{2 t} M I P S_{1 t}
$$

34 We choose this functional form as opposed to the traditional log-log because it simplifies the computation of the $\hat{x_{t}}+k$ 's. The next chapter will investigate the sensitivity of our index to this choice.

35 Berndt, Showalter and Woolridge (1990) examine the sensitivity of hedonic price indexes for computers to the choice of functional form on the hedonic surface. 
We evaluate (5.2) at the observed levels of $M I P S_{i t}$ to obtain a vector of estimated marginal prices for MIPS for each year. We then pool these vectors of marginal prices together to get mip mips $_{\text {. }}$

We then estimate demand by estimating

$$
\hat{m P}_{\text {mips, } 1}=\alpha_{0}+\alpha_{1} M I P S_{1}+B_{1} \Omega+\eta_{1}
$$

by two-stage least squares using the instrumental variables described in the previous section. ${ }^{36}$ Here $B_{i}$ represents the matrix of buyer characteristics for buyer $\mathrm{i}$. For the instrumental variable "neighbors", we chose to include the nine closest systems in characteristics space as measured by Mahalanobis distance. ${ }^{37}$ The results of the estimation of (5.3) are given in Table 5.2.

Table 5.2 shows that the coefficient on MIPS is negative and significant implying downward sloping demand. The results also show that none of the SIC group coefficients are significantly different from zero using a $5 \%$ level of significance. However, it is also important to test whether they are different from each other. Unfortunately, the coefficients are significantly different from each other in only a few instances. All of the other buyer characteristics, except Age of the Youngest System, are significant.

Based on the estimate of (5.3) along with the estimates of (5.1) we proceed to compute the forward index for each year as described in the Methodology. The results of this computation are given in Tables 5.3A and 5.3B.

Looking at the 1985 column (which is the index computed using the 1985 buyers) we see that the index has an average annual growth rate (shown in the last row) which is slower than that found in previous studies. ${ }^{38}$ However, we are looking at a different time period than other

36 This demand curve is derived from a bid curve of the form $P_{1}=Y_{0} M I P S_{1}+Y_{1} M I P S_{1}^{2}$ where

$$
Y_{0}=\alpha_{0}+B_{i} \Omega \text { and } Y_{1}=\alpha_{1} / 2
$$

37 We chose nine systems because all of their coefficients were significant in the first stage regression and this was the most we could include due to computing constraints. 
studies, so we will need to compare these results with a price index computed in the traditional fashion. We will do this below. Second, we also see that as we move across the tables the growth rates increase. This implies that our utility-based index computation is potentially sensitive to the set of buyers we use as weights.

Finally, we note the rise in the index between 1985 and 1986 when using the 1985 buyers. Recall that after examining Figure 5.1 we believed this might occur. The economic interpretation of this is that the price per performance in 1985 was lower than that in 1986 for a portion of the product space, and as a consequence buyers could achieve a higher utility level in 1985 . However, we do note that the surfaces cross at two levels of MIPS-approximately 0.8 and 16.5 . The 1985 surface lies above the 1986 surface between these two points. This implies that not all buyers were better off in 1985 than 1986. The computed price indexes say that on average, though, buyers were better off in 1985 than 1986.

One way to attempt to incorporate the changing sets of buyers into a single index would be to "link" the adjacent indexes together. Assuming that we are better at predicting what a buyer would purchase in the next period rather than two or more periods ahead, we can place the 1985 buyers into 1986, the 1986 buyers into 1987 , etc., choose some year as our base and then link these indexes together. We do this in Table 5.5 using both $P^{*}$ and $P^{0}$ as our weights. We see that these indexes have growth rates lower than the traditional hedonic and still pick up the increase from 1985 to 1986 . These indexes decline more rapidly, though, than the utility indexes of Tables 5.3A and 5.3B using the 1985 buyers. This is because more weight is being given to buyers at higher levels of MIPS who benefit more from improvements in technology than those at lower levels.

At this juncture we are curious how the estimated rates of benefits to buyers compares with the average price change across all systems. Such a comparison give us information about the percentage of buyers who did (and did) not receive large benefits from increases in the product space. To compare our utility-base indexes with changes in constant-quality prices, we need to compare our index with a traditional hedonic index. For the sake of thoroughness, we

38 Brown (1994) shows that it makes little difference whether we use $P^{*}$ or $P^{0}$ as our weight. 
compute two traditional hedonic indexes, shown in Table 5.4. In the first column we compute the index using a log-log functional form and in the second column we compute the index using a loglinear functional form

Both of these hedonic indexes have an average annual growth rate more than two times higher than those shown in the 1985 columns of Tables 5.3A and 5.3B. Here we see that while both the $\log$-log and $\log$-linear price indexes overstate the benefits to buyers resulting from the shifts in the hedonic surface, the log-linear index does pick up the retrogression from 1985 to $1986{ }^{39}$ Overall, the hedonic indexes decline at a faster rate than our cost of living indexes.

In order to get a better understanding of the comparison, we produced a boxplot showing the distribution of buyers across MIPS over time. This is shown in Figure 5.2. The shaded regions in the boxplot represent the interquartile range and the white line in the shaded region represents the median. It is clear from the figure that the distribution of observed purchases is changing over time. In fact, the maximum observed purchase in 1985 is nearly the median purchase by 1991. If all buyers benefit by exactly the same amount from improvements in technology, then this fact will not matter. However, Tables 5.3A and 5.3B show that buyers do not benefit by the same amount, i.e., as shown by the changing'growth rates of the indexes over time. Thus, the base of buyers is quite important for utility-based indexes and welfare inferences. This observation is masked by the traditional hedonic index.

What is more important, Figure 5.2 reveals the intuition behind our estimates. Despite extremely rapid declines in price per unit of computing capacity, the growth in the size of acquisitions increases only slowly. Most buyers bought "small" systems and continue to do so in later years, despite rapid decline in prices. As we explored extensively in Brown [1994], our model of individual buyer behavior has to represent this slow aggregate movement as relatively inelastic demand for most buyers. Hence, the utility-based index has to decline at a slower rate than the quality adjust price index. The only open questions are issues of degree. While we have placed a particular functional form on our estimates for ease of computation and exposition, with

39 The log-linear hedonic index rises between 1985 and 1986, whereas the log-log index does not. This is evidence that the choice of functional form is important when computing these indexes. This is very interesting because almost all previous studies have employed a $\log$-log form and have rarely tested it against any other forms. 
behavior like this, the functional form is of secondary importance for determining the qualitative results. Virtually any version of a Rosen model would give a big difference between the utilitybased index and a quality adjusted price index.

We next compute our "reverse" index. This is shown in Table 5.6. Again, we see rates of growth lower than the traditional hedonic and we see changing rates of growth depending on the set of buyers we use as weights. This index also rises between 1985 and 1986 except when we weight by the 1986 buyers. This is because, on average, more 1986 buyers were better off in 1986 than 1985. This is the opposite of what happened when we computed the forward index and weighted by 1985 buyers. This is further evidence that the distribution of buyers one uses as weights is important. Table 5.7 shows the reverse linked index. The growth rate is lower than the traditional hedonic yet faster than the reverse index using the 1991 buyers as weights.

As a final step with this one characteristic model, we recompute all of the indexes using only the IBM and plug-compatible acquisitions as suggested by Dulberger (1989). She suggested this because of the noncomparability of MIPS ratings between IBM and plug-compatible systems with others. These indexes are given in Tables 5.8A-5.12.

All of the indexes are virtually identical in their counterparts using the entire data set. This is not surprising since approximately $80 \%$ of the acquisitions over this time period are IBM or IBM compatible. Figure 5.3 shows a boxplot of the distribution of MIPS using only the IBM and plug-compatible data. Comparing this with Figure 5.2 we see that the distributions are also almost identical. These results imply that at least for econometric purposes, the distinction between these two sets of data may be unnecessary.

This section has focused on estimating our benefit index and comparing our utility index with a traditional hedonic index using a single characteristic. In the next section we add more computer characteristics to provide a more complete description of the product.

\subsection{Three Characteristic Model}

We now extend our description of a mainframe computer by adding minimum and maximum memory as characteristics. We choose this description because it closely resembles the 
descriptions used in previous research. ${ }^{40}$ While we are choosing this set of characteristics, we do not believe that this is a complete description of a mainframe computer as stated by Dulberger [1989]. Unfortunately, there are little, if any, other measured characteristics available to researchers. Future work could look into a better characterization of the computer system.

As in the one characteristic case, we begin by estimating a hedonic surface for each year of the form

$$
\begin{aligned}
& P_{i t}=\beta_{0 t}+\beta_{1} M I N \cdot M E M+\beta_{2} M I P S+\beta_{3} M A X . M E M \\
& +\beta_{4} M I N . M E M^{2}+\beta_{5} M I P S^{2}+\beta_{6} M A X . M E M^{2}+u_{i t}
\end{aligned}
$$

We do not include interactions among the variables in the specification of (5.4) because it does not largely alter one's conclusion. We consider this issue in Brown [1994]. The estimation results are given in Table 5.13.

The results show that for the most part the coefficients are significant. In addition, all $\mathbf{R}^{2}$ values are above 0.92 . Three coefficients, MAX.MEM in 1985, MIN.MEM in 1986 and $M A X . M E M$ in 1990, are the wrong sign (MAX.MEM in 1990 is not significantly different from zero). This is possibly due to a high correlation between MIN.MEM and MAX.MEM. This correlation is 0.76 . However, believing this to be a more correct set of characteristics than a MIPS - MIN.MEM or MIPS - MAX.MEM specification, we choose to maintain it.

We next compute the predicted marginal prices and estimate the following demand equations:

$$
\begin{aligned}
& m p_{\min , 1}=\alpha_{10}+\alpha_{11} \text { MIN.MEM }+B_{i} \Omega_{1}+\eta_{1 i}, \\
& m p_{\text {mips,i }}=\alpha_{20}+\alpha_{21} \text { MIPS }+B_{1} \Omega_{2}+\eta_{21}, \\
& m p_{\text {max }, i}=\alpha_{30}+\alpha_{31} \text { MAX.MEM }+B_{1} \Omega_{3}+\eta_{31}
\end{aligned}
$$

40 See Triplett (1989) for a list of studies and their choice of characteristics. 
We estimate each equation in (5.5) separately using two-stage least squares with the instruments described in Section 4.4. We decided not to include all three characteristics on the right hand side of each equation because the additively separable demand function does an adequate job. ${ }^{41}$ The above specification produced reasonable results. Table 5.14 gives the correlation matrix of the computer characteristics. Tables 5.15-5.17 give the demand estimation results.

Each of the demand equations is downward sloping. The SIC dummy variables are again rarely significantly different from the excluded group or each other. The remaining buyer characteristics, except Total KVA and the IBM dummy in minimum memory demand and Age Young in maximum memory demand, are significant.

With these results, we proceeded to compute our forward index, shown in Tables 5.18A and 5.18B. The traditional hedonic indexes are given in Table 5.19. The indexes closely resemble those of the one characteristic model. The significant difference is that the three characteristic index has a higher growth rate than the one characteristic index. This should be expected since we are now allowing innovation to take place in different characteristic dimensions. Allowing this innovation permits buyers to obtain benefits they could not obtain in the one characteristic case.

Finally, we again see that these indexes rise between 1985 and 1986 when we weight by the 1985 buyers. However, it is not clear if this is due to technological retrogression in all characteristic dimensions or some subset of the dimensions. The hedonic indexes shown in Table 5.19 also look similar to the hedonic indexes computed for the one characteristic case. Again, the log-linear model is the only one to detect the retrogression from 1985 to $1986 .^{42}$

As seen in the one characteristic case, the growth rates increase as we weight by later sets of buyers. Figures 5.4 and 5.5 show boxplots for the distributions of minimum and maximum memory. Again we see that the maximum purchase in 1985 is nearly the median purchase by 1991. The changes in these distributions along with the changes in the MIPS distribution significantly affect the growth rates we see as we weight by later sets of buyers. This continues to support the claim made in section 5.1 that most buyers bought "small" systems and continue to do

41 High correlation in the features of available systems results in a number of econometric difficulties which unnecessarily complicate the estimation without contributing additional insight into the structure of demand.

42 This further supports the earlier claim that the choice of functional form for the hedonic surface is a key aspect in computing a hedonic or utility index. 
so in later years. Again, since prices declined so rapidly over the period, our model of individual buyers has to represent this behavior as relatively inelastic demand for most buyers. Hence, the utility-based index has to decline at a slower rate than the quality adjust price index. Again, we are firm in our conclusions that virtually any functional form of a Rosen model estimated on this data would give a big difference between the utility-based index and a quality adjusted price index.

Tables 5.20-5.22 present the forward linked, reverse and reverse linked indexes. They convey much of the same information provided by their one variable counterparts. The interesting feature of these is the growth rates of the linked indexes. Each has a rate higher than the loglinear hedonic rate, but lower than the $\log -\log$ hedonic rate. While we have been arguing that the utility index is superior to the hedonic index in measuring the benefits of innovation to buyers, we also realize that the results obtained from a utility index are sensitive to the set of buyers used as a base. For example, the forward linked index using $P^{*}$ as the weight has a growth rate of $-30.38 \%$ from 1985-1991. If we exclude 1991, the growth rate is $-16.38 \%$. In order to try to overcome this sensitivity, we have proposed that a linked index may be appropriate since the final index is not dependent on a single set of buyers. In this three characteristic case, both our linked index and the hedonic index perform about the same in the long run. However, there is considerable variation in the short run.

The faster rate of decline in the linked index for the three characteristic case is a result of the enormous rate of growth for the 1990 buyers facing the 1991 hedonic surface. For example, the growth rate using $P^{*}$ as a weight is over 100 percent between 1990 and 1991 using the 1990 buyers. That growth rate is never more than 54 percent using the other sets of buyers. This suggests that one might average the growth rates over all sets of buyers to get a linked index. We compute this for the forward index using $P^{*}$ as a weight. This yields the index given in Table 5.23. Notice that now the growth rate is $21.44 \%$, which is well below the $P^{*}$ linked index growth rate given in Table 5.20 and well below the growth rates of the hedonic indexes.

While the linked index computed previously was less dependent on the set of buyers than the utility index using a single set of buyers, computing the index in this fashion (averaging the growth rates over all sets of buyers) is even less dependent on the sets of buyers. While this is a nice feature of this index, it also has drawbacks. The main drawback is that it gives weight to 
buyers who are being projected far into the future. The farther we project into the future, the greater possibility of hitting a corner. Buyers who hit the corner do not receive as much benefit as they would have had they purchased what was optimal. This implies that we should concentrate on projecting only a short time into the future.

Tables 5.24A-5.29 recompute all of the indexes of the three characteristic model using only the IBM and plug-compatible acquisitions. The utility and hedonic indexes change very little from their counterparts using all of the acquisitions. The most notable feature is that they all have higher growth rates than the "all data" indexes. ${ }^{43}$ This implies that price per performance in IBM systems fell faster over the time period than the overall rate. Since the distributions of characteristics purchased do not seem to be drastically different between IBM and the entire data set, it must either be the case that IBM was lowering its prices at a faster rate than the overall rate, or that there is some unmeasured characteristic which is causing IBM's price per performance to fall relative to the other systems in the sample. This is interesting and needs to be investigated further by attempting to expand the set of measured characteristics.

\section{Summary and Closing Remarks}

In this paper we have employed an extensive micro-dataset on the mainframe computer market from 1984-1991. We describe an alternative procedure based on Rosen [1974], Bartik [1987], Epple [1987] and Trajtenberg [1990]. Using this method we have computed indexes which account for the benefits buyers receive from improvements in new technology.

We have computed a large number of indexes. There are three main points made by the results. First, benefits received by buyers, as measured by a price equivalent utility index, must account for declining marginal utility of characteristics. If so, the fall in the utility index is much slower than the fall in the constant-quality price index. Second, the distribution of buyers across the product space strongly influences the benefits from technical change. In this instance, buyers are largely concentrated at the lower levels of the characteristics space. Hence, very few buyer benefit from increases in the product space. Third, our utility index shows that, in mainframe

43 Note that these indexes are plagued by the 1991 problem described earlier. Removing 1991 results in a significantly lower growth rate. 
computers, the constant-quality price index overstates buyer benefits by a significant margin. If innovation must be measured in terms of its value to buyers, then based on the results presented here, one must be skeptical of the inferences solely drawn from the traditional hedonic price index regarding changes to economic welfare.

Our results also expand on Trajtenberg [1990], who described situations where hedonic methods would fail to account for technological change. The first failure he described was associated with the introduction of new systems which "filled-in" the product space. ${ }^{44}$ By construction, our utility based index does not account for this factor. On the one hand, this should not worry us since this factor is less important in an industry where buyers may easily customize their system and where the product is crowded, as in mainframes. On the other hand, incompatibilities between platforms induce potentially unobserved "gaps" in the product space and we have not accounted for this factor. Second, Trajtenberg argued that innovation which extends the range of the product space also is not measured by a traditional hedonic. We agree that the welfare benefits from technical change cannot be understood without examining extension of product space. In contrast, however, we find that it is less important for mainframes in the 1980s than it was for CT scanners in the 1970s. ${ }^{45}$ The main reasons for these differences had to do with the distribution of buyers and the distribution of elasticities of demand. In short, very few buyers needed larger systems with the extra computing capacity.

We noted throughout the study that the results were obtained while maintaining a specific functional form for the hedonic surfaces in the first step of the computation of our index. We noted throughout the problems with using MIPS as a system characteristic and using acquisitions from both IBM and non-IBM vendors. We compared results using both sets of data, and for the most part there was little change in our qualitative results. In Brown [1994] we investigated the robustness of our results to various alternative functional forms of our model. The conclusions also do not substantially change. However, this still leaves open issues associated with the robustness of our conclusions to different models of demand. Do the Rosen model or alternative

\footnotetext{
44 Because the new systems, by design, lie on the already existing hedonic surface, a hedonic index would not register any innovation. For a more complete description of these two cases see Trajtenberg (1990).

45 See Greenstein [1994] for an argument that Trajtenberg's analysis more closely matches the market for computing in the 1960s and 1970s.
} 
demand models of differentiated product markets -- for example, a multinomial logit model -provide similar quantitivative and qualitative insights about demand elasticities, welfare benefits, and so on? These issues will take substantial work, and we hope to address them in future research.

Finally, we close with several observations about the implications of our study for innovation in this industry more generally. Our conclusions lend support to the view, often stated but incompletely espoused in the trade-press, that the computer industry is passing into a new era. We agree that the contrast with earlier eras is sharp. Rates of decline in price per unit of computing could not be any faster today. Yet, similar innovation in the 1960s and 1970s induced buyers to adopt and develop larger capacity mainframe systems, each generation enabling new functionality. In our study of the 1980s, this adoption pattern is not as evident.

There are at least two related economic issues behind the adoption pattern in this data. First, it is valuable to distinguish between "normal" data processing and "leading-edge" data processing (The latter is often called "bleeding edge"), where we recognize that the former is more typical than the latter. In our study, it is the leading-edge user who adopts larger systems, taking advantages of changes in the product space. Most of these applications were novel and large on-line transaction processing applications. Many of these received attention within the contemporaneous trade-press. Although these activities were interesting as computer-engineering feats, our data show that they were unrepresentative as economic events. Hence, we conjecture that one key to understanding buyer benefits from innovation involves understanding why leading edge data processors are willing to adopt systems on technical frontiers when others are not. Is this due largely to differences in adoption costs or adoption benefits? Was the leading edge user of the 1980s unusually slow in response to price change and new technological opportunities? Was the normal data processing user unusually slow to follow the leading edge?

A related open issue concerns the relationship between our study's conclusion and the widely-noted behavior that traditional mainframe buyers are investing less in mainframes and investing more in smaller computing platforms. This second topic raises fundamental questions about welfare from innovation when buyers incur large switching costs, when buyers spread their capital purchases across a variety of computing platforms, and when technical change unevenly 
impacts different parts of a differentiated product market. We have made a step towards understanding these problems, but these issues also require further analysis of, as well as extensive use of, data on buyer computing choice among competing platforms. 


\section{Bibliography}

Bailey, M. N. and Gordon, R.J. [1992], "The Productivity Slowdown, Measurement Issues, and the Explosion of computer Power," Brookings Papers on Economic Activity.

Bartik, T.J. [1987]. "The Estimation of Demand Parameters in Hedonic Price Models." Journal of Political Economy, 95(1), 81-88.

Berndt, E.R.[1991]. The Practice of Econometrics: Classic and contemporary. Reading, MA: Addison-Wesley.

Berndt, E.R. \& Griliches, Z. [1990]. Price Indexes for Microcomputers: An Exploratory Study. National Bureau of Economic Research Working Paper No. 3378.

Berndt, E.R., and Morrison, C., [1995] "High-Tech Capital Formation and Economic Performance in US Manufacturing Industries -- an Exploratory Analysis," Review of Economics and Statistics, Jan, V65, pp 9-43.

Berndt, E.R., Showalter, M.H. \& Woolridge, J.M. [1990]. "On the Sensitivity of Hedonic Price Indexes for Computers to the Choice of Functional Form." Manuscript from the Massachusetts Institute of Technology.

Berry, S., Levinsohn, J. \& Pakes, A.[1993]. "Automobile Prices in Market Equilibrium: Part I and II." National Bureau of Economic Research Working Paper No. 4264.

Bresnahan, T. [1987], "Measuring the Spillover from Technical Advance: Mainframe Computer in Financial Services," American Economic Review, March.

Bresnahan, T. and Greenstein, S., [1992]. "Technological Competition and the Structure of the Computer Industry," CEPR Discussion Paper No. 315, Stanford University, June 1992.

Bresnahan, T., and Greenstein, S., [1994], "The Competitive Crash in Large Scale Commercial Computing." in (Eds) Gavin Wright and Ralph Landau, Growth and Development: The Economics of the 2Ist Century.

Bresnahan, T., and Greenstein, S., and Ito, H. [1995], "The Irreversibility of Large Investment in Computer Technology," mimeo, Stanford University.

Bresnahan, T., and Saloner, G., [1995], "Large Firms Demand for Computer Products and Services: Competing Market Models, Inertia, and Enabling Strategic Change," mimeo, Stanford University

Brown, J.N., \& Rosen, H.S., [1982], On the estimation of structural hedonic price models Econometrica, 50(3), 765-768.

Brown, K. H. [1994], Estimating the Economic Benefits of Advances in Computer Technology. Unpublished Ph.D. dissertation, University of Illinois.

Brown, K. H. and Greenstein, S. [1994], "A Geometric and Analytical Comparison of a Cost of Living Index and a Hedonic Index," mimeo, University of Illinois.

Brynolfsson, E., and Hitt, L. [1994], "Information Technology as a Factor of Production: the Role of Differences Among Firms" Mimeo, Sloan School of Management.

Brynolfsson, E. [1993], "The Productivity Paradox of Information Technology," Communications of the $A C M, 36$ (12), December. pp. 67-77.

Chow, G.C. [1967]. Technological change and the demand for computers. American Economic Review, 57(December), 1117-1130.

Cole, R., Chen, Y. C. , Barquin-Stolleman, Y. C., Dulberger, E., Helvacian, N., Hodge, J., 
[1986], "Quality Adjusted Price Indexes for Computer Processors, Selected Peripheral Equipment," Survey of Current of Business 66 (Jan), PP 41-50.

Diamond, D.B., Jr. \& Smith, B.A. [1985], Simultaneity in the Market for Housing Characteristics, Journal of Urban Economics, 17, 280-292.

Diewart, W. E. [1986], "Exact and Superlative Index Numbers," Journal of Econometrics, 4, pp. $115-145$.

Dulberger, E.R. [1989], "The Application of a Hedonic Model to a Quality-Adjusted Price Index for Computer Processors." In D.W. Jorgenson \& R. Landau (eds.), Technology and capital formation. Cambridge, MA: The MIT Press.

Epple, D. [1987], Hedonic Prices and Implicit Markets: Estimating Demand and Supply Functions for Differentiated Products. Journal of Political Economy, 95(1), 59-80.

Feenstra, R. C. [1995], "Exact Hedonic Price Indexes," NBER Working Paper Number 5061, March.

Feenstra, R. C. [1993], "Measuring the Welfare Effect of Quality Change: Theory and Application to Japanese Autos," NBER Working Paper Number 4401, July.

Fisher, F. M. and Griliches Z., [1995], "Aggregate Price Indices, New Goods, and Generics." Quarterly Journal of Economics, February, 229-244.

Fisher, F. M. and Shell K. [1972], The Economic Theory of Price Indexes, New York: Academic Press.

Flamm, K. [1987], Targeting the Computer: Government Support and International Competition, Washington D.C.: The Brookings Institute.

Friedman, A. L., and Cornford D.S. [1989], Computer Systems Development: History, Organization and Implementation, John Wiley and Sons, New York, NY.

Gordon, R. J. [1990], The Measurement of Durable Goods Prices, University of Chicago Press, 1990.

Gordon, R. J. [1989], "The Postwar Evolution of Computer Prices," in Technology and Capital Formation, Edited by Dale W. Jorgenson and Ralph Landau, MIT Press.

Greenstein, S. [1992], "Did Installed Base Give an Incumbent any (Measurable) Advantages in federal Computer Procurement?" Rand Journal of Economics, 24(1), pp. 19-39.

Greenstein, S. [1995], "From Super-minis to Super Computers: Estimating Surplus in the Computing Market." in (Eds) Tim Bresnahan and Robert J. Gordon, The Economics of New Products, National Bureau of Economic Research, University of Chicago Press.

Greenstein, S. [1994], "Did Computers Diffuse Quickly? Best Versus Average Practice in Mainframe Computers, 1968-1983." Working Paper No. 4647, National Bureau of Economic Research, Cambridge, MA. February.

Griliches, Z. [1994], "Productivity, R\&D and the Data Constraint," American economic Review, March 1-23, 1994.

Hastie, T.J. \& Tibshirani, R.J. [1990]. Generalized additive models. Vol. 43 of Monographs on Statistics and Applied Probability. New York: Chapman and Hall.

Hendel, I. [1994], "Estimating Multiple-Discrete Choice Models: An application to Computerization Returns," Technical working paper no 168, NBER, Oct.

Ito, H. [1995], "The Structure of Investment Costs in Mainframe Computer Investment," mimeo, Stanford University. 
Lichtenberg, F. [1993], "The Output contributions of Computer Equipment and Personnel: A Firm Level Analysis," Columbia Business School, October.

Loveman, G. W., [1994], "An Assessment of the Productivity Impact of Information Technologies," in Thomas J. Allen and Michael S. Scott Morton (eds) Information Technology and the corporation of the 1990s, Research Studies, Oxford University Press, New York.

Mendelson, H., [1985], Pricing Computer Services: Queuing Effects, "Communications of the $A C M, 28(3)$, pp. 312-321.

Oliner, S. [1992], Constant-Quality Price Change, Depreciation, and Retirement of Mainframe Computers. Manuscript from the Board of Governors of the Federal Reserve System, Division of Research and Statistics.

Rosen, S. [1974], Hedonic Prices and Implicit Markets: Product Differentiation in Pure Competition. Journal of Political Economy, 82, 34-49.

Sichel, D. and Oliner, S. [1994], "Computers and Output Growth Revisited: How Big is the Puzzle?" Forthcoming, Brookings Paper of Economic Activity.

Trajtenberg, M. [1989], "The Welfare Analysis of Product Innovations, with an Application to Computed Tomography Scanners," Journal of Political Economy, 97, 2, April.

Trajtenberg, M. [1990], Economic analysis of product immovation. Cambridge, MA: Harvard University Press.

Triplett, J. E. [1989], Price and technological change in a capital good: A survey of research on computers. In D.W. Jorgenson \& R. Landau (eds.), Technology and Capital Formation. Cambridge, MA: The MIT Press.

Witte, A.D., Sumka, H.J. \& Erekson, H. [1979]. An Estimate of a Structural Hedonic Price Model of the Housing Market: An Application of Rosen's Theory of Implicit Markets. Econometrica, 47(5), 1151-1173. 
Table 4.1

Descriptive Statistics for Price

\begin{tabular}{|c|c|c|c|c|c|}
\hline Year & Minimum & Median & Mean & Maximum & Std. Dev. \\
\hline 1985 & 0.00 & 390.70 & 1033.00 & 9200.00 & 1491.11 \\
1986 & 0.00 & 656.30 & 1833.00 & 23910.00 & 2983.82 \\
1987 & 0.00 & 608.80 & 1808.00 & 31740.00 & 3050.31 \\
1988 & 0.00 & 734.90 & 2284.00 & 43990.00 & 3828.61 \\
1989 & 0.00 & 707.10 & 2476.00 & 44790.00 & 4177.20 \\
1990 & 0.00 & 821.80 & 3039.00 & 40680.00 & 5158.61 \\
1991 & 0.00 & 777.40 & 2925.00 & 34740.00 & 5092.07 \\
\hline Total & 0.00 & 638.70 & 2104.00 & 44790.00 & $\ddots 3716.81$ \\
\hline
\end{tabular}

Table 4.2

Descriptive Statistics for Minimum Memory

\begin{tabular}{|c|c|c|c|c|c|}
\hline Year & Minimum & Median & Mean & Maximum & Std. Dev. \\
\hline 1985 & 0.032 & 4.096 & 6.767 & 32.77 & 7.50 \\
1986 & 0.032 & 4.096 & 14.320 & 65.54 & 19.92 \\
1987 & 0.032 & 8.192 & 18.290 & 131.10 & 26.59 \\
1988 & 0.060 & 16.380 & 29.890 & 131.10 & 37.42 \\
1989 & 0.008 & 16.380 & 37.880 & 165.50 & 44.32 \\
1990 & 0.032 & 24.580 & 46.710 & 262.10 & 47.07 \\
1991 & 0.100 & 32.770 & 53.360 & 262.10 & 49.15 \\
\hline Total & 0.008 & 10.240 & 26.450 & 262.10 & 36.84 \\
\hline
\end{tabular}


Table 4.3

Descriptive Statistics for Maximum Memory

\begin{tabular}{|c|c|c|c|c|c|}
\hline Year & Minimum & Median & \multicolumn{1}{c|}{ Mean } & Maximum & Std. Dev. \\
\hline 1985 & 0.256 & 24.58 & 33.50 & 262.10 & 31.22 \\
1986 & 0.256 & 32.77 & 65.54 & 262.10 & 80.36 \\
1987 & 0.256 & 32.77 & 75.97 & 524.30 & 110.03 \\
1988 & 0.512 & 40.96 & 279.00 & 2097.00 & 559.75 \\
1989 & 0.032 & 65.54 & 374.40 & 3146.00 & 686.35 \\
1990 & 0.064 & 81.92 & 732.70 & 4194.00 & 1227.92 \\
1991 & 0.512 & 262.10 & 1102.00 & 4719.00 & 1456.48 \\
\hline Total & 0.032 & 32.77 & 277.10 & 4719.00 & 697.95 \\
\hline
\end{tabular}

Table 4.4

Descriptive Statistics for MIPS

\begin{tabular}{|c|c|c|c|c|c|}
\hline Year & Minimum & Median & Mean & Maximum & Std. Dev. \\
\hline 1985 & 0.10 & 2.70 & 5.21 & 28.00 & 6.39 \\
1986 & 0.20 & 3.40 & 8.15 & 33.50 & 9.03 \\
1987 & 0.10 & 4.20 & 9.31 & 49.00 & 11.21 \\
1988 & 0.20 & 6.50 & 15.55 & 75.00 & 19.05 \\
1989 & 0.10 & 7.90 & 21.24 & 114.00 & 26.61 \\
1990 & 0.20 & 14.00 & 29.56 & 114.40 & 33.64 \\
1991 & 0.40 & 21.60 & 35.36 & 114.40 & 36.58 \\
\hline Total & 0.10 & 5.70 & 15.28 & 114.40 & 22.35 \\
\hline
\end{tabular}




\begin{tabular}{|c|c|}
\hline \multicolumn{2}{|r|}{$\begin{array}{l}\text { Table } 4.5 \\
\text { Definitions of the Buyer Characteristics }\end{array}$} \\
\hline Variable & Definition \\
\hline SIC & $\begin{array}{l}\text { The standard industrial classification code of the site. These SICs } \\
\text { are grouped into } 24 \text { two-digit groups. They are: 1-18 (Natural } \\
\text { Resources; NATRES), 20-26 \& } 29 \text { (Refining and other manufacturing; } \\
\text { REFMAN), } 27 \text { (print, publishing, etc; PUB), } 28 \text { (Chemicals; CHEM), } \\
30-34 \& 38 \text { \& } 39 \text { (Fabrication and misc. manufacturing; FABMAN), } \\
35 \text { (Computer manufacturing; COMP), } 36 \text { (Other electrical equipment; } \\
\text { ELEQUIP), } 37 \text { (Transportation equipment; TRANSP), } 40-47 \text { (Misc. } \\
\text { utilities; UTI), } 48 \text { (Communication; COMM), } 49 \text { (Electricity; } \\
\text { ELECTRIC), 50 (Wholesale trade; WHOLE), 51-59 (Retail trade; } \\
\text { RETAIL), } 62 \text { \& } 64-69 \text { (Misc. finance; FIN), } 60 \text { (Depository } \\
\text { institutions; DEPOSIT), 61 (Credit institutions; CREDIT), } 63 \\
\text { (Insurance; INS), 70-79 (Misc. business services; BUSSERV), } 81 \text { \& } \\
83-89 \text { (Misc. social services; SOCSERV), } 80 \text { (Health services; } \\
\text { HEALTH), } 82 \text { (Education; EDU), 90 \& 92-96 \& 98 \& 99 (Misc. } \\
\text { government; GOV), 91 (Administrative government; ADGOV), } 97 \\
\text { (Defense; DEFENSE). These are dummy variables which take the } \\
\text { value } 1 \text { if the site is in the SIC grouping and 0 otherwise. The label } \\
\text { in ALL CAPS will be used to identify the SIC group from this point } \\
\text { forward. }\end{array}$ \\
\hline IBM & $\begin{array}{l}\text { A dummy variable which takes the value } 1 \text { if the site had any } \\
\text { IBM medium to large system and } 0 \text { otherwise. }\end{array}$ \\
\hline Site Value & $\begin{array}{l}\text { The estimated purchase value of the site in } 1,000 \text { s of dollars. This } \\
\text { amount was turned into real dollars by adjusting for the Producer Price } \\
\text { Index. }\end{array}$ \\
\hline Maximum MIPS & $\begin{array}{l}\text { The number of MIPS on the system at the site with the largest } \\
\text { MIPS rating. }\end{array}$ \\
\hline Total MIPS & The sum total MIPS of all systems at the site. \\
\hline Total KVA & The sum total of the KVA ratings of all systems at the site. \\
\hline Age Young & $\begin{array}{l}\text { The technical age (year of observation minus the vintage of the } \\
\text { system) of the youngest system at the site. }\end{array}$ \\
\hline
\end{tabular}




\begin{tabular}{|l|r|r|r|r|r|r|r|}
\hline \multicolumn{7}{|c|}{ Tumber of l's for SIC Dummy Variables } \\
\hline \multicolumn{1}{|c|}{ Group } & 1985 & 1986 & 1987 & 1988 & 1989 & 1990 & 1991 \\
\hline REFMAN & 154 & 165 & 255 & 162 & 177 & 122 & 25 \\
PUB & 60 & 77 & 99 & 65 & 76 & 70 & 7 \\
CHEM & 55 & 67 & 111 & 82 & 84 & 62 & 16 \\
FABMAN & 184 & 189 & 234 & 160 & 178 & 96 & 25 \\
COMP & 112 & 150 & 151 & 137 & 157 & 115 & 24 \\
ELEQUIP & 137 & 134 & 171 & 176 & 116 & 81 & 17 \\
TRANSP & 90 & 96 & 99 & 105 & 104 & 63 & 18 \\
UTIL & 77 & 90 & 112 & 88 & 85 & 87 & 18 \\
COMM & 42 & 98 & 88 & 132 & 96 & 81 & 21 \\
ELECTRIC & 81 & 95 & 115 & 108 & 89 & 100 & 20 \\
WHOLE & 132 & 113 & 138 & 108 & 97 & 57 & 13 \\
RETAI & 174 & 174 & 249 & 212 & 277 & 185 & 48 \\
FIN & 57 & 80 & 106 & 107 & 73 & 65 & 23 \\
DEPOSIT & 194 & 247 & 307 & 247 & 311 & 207 & 51 \\
CREDIT & 68 & 96 & 104 & 111 & 48 & 29 & 9 \\
INS & 192 & 210 & 287 & 255 & 237 & 202 & 65 \\
BUSSERV & 360 & 361 & 525 & 495 & 486 & 457 & 115 \\
SOCSERV & 60 & 61 & 70 & 64 & 84 & 75 & 35 \\
HEALTH & 141 & 108 & 177 & 157 & 174 & 146 & 35 \\
EDU & 170 & 162 & 225 & 174 & 173 & 173 & 39 \\
GOV & 130 & 165 & 230 & 191 & 237 & 139 & 50 \\
ADGOV & 140 & 132 & 153 & 153 & 156 & 115 & 19 \\
DEFENSE & 74 & 104 & 123 & 105 & 76 & 76 & 18 \\
\hline
\end{tabular}




\begin{tabular}{|c|c|c|c|c|c|}
\hline \multicolumn{6}{|c|}{ Table 4.7 } \\
\hline Year & Minimum & Median & Mean & Maximum & Std. Dev. \\
\hline 1985 & 372.10 & 7442.00 & 14880.00 & 62140.00 & 15836.80 \\
1986 & 364.60 & 7657.00 & 21900.00 & 68370.00 & 22590.74 \\
1987 & 179.10 & 9311.00 & 19510.00 & 106500.00 & 23889.48 \\
1988 & 175.00 & 10850.00 & 28540.00 & 140000.00 & 36429.42 \\
1989 & 33.67 & 11200.00 & 28880.00 & 138900.00 & 37127.44 \\
1990 & 65.09 & 10580.00 & 26810.00 & 113900.00 & 32140.17 \\
1991 & 39.46 & 11050.00 & 21570.00 & 94710.00 & 26235.58 \\
\hline Total & 33.67 & 9311.00 & 23450.00 & 140000.00 & 29611.84 \\
\hline
\end{tabular}

\begin{tabular}{|c|c|c|c|c|c|}
\hline \multicolumn{7}{|c|}{ Table 4.8 } \\
\hline Year & Minimum & Median & Mean & Maximum & Std. Dev. \\
\hline 1985 & 0.10 & 1.40 & 3.92 & 99.00 & 6.12 \\
1986 & 0.10 & 2.70 & 6.07 & 80.00 & 8.15 \\
1987 & 0.10 & 2.70 & 6.81 & 99.00 & 10.30 \\
1988 & 0.10 & 5.00 & 11.80 & 99.00 & 15.51 \\
1989 & 0.00 & 6.40 & 14.87 & 104.00 & 19.47 \\
1990 & 0.10 & 9.50 & 22.21 & 114.40 & 27.74 \\
1991 & 0.10 & 13.00 & 29.35 & 114.40 & 35.52 \\
\hline Total & 0.00 & 4.00 & 11.36 & 114.40 & 18.25 \\
\hline
\end{tabular}


Table 4.9

Descriptive Statistics for Total MIPS

\begin{tabular}{|c|c|c|c|c|c|}
\hline Year & Minimum & Median & Mean & Maximum & Std. Dev. \\
\hline 1985 & 0.10 & 2.20 & 7.47 & 181.00 & 14.95 \\
1986 & 0.10 & 3.80 & 13.39 & 205.10 & 24.64 \\
1987 & 0.10 & 3.80 & 14.08 & 325.00 & 27.38 \\
1988 & 0.10 & 6.90 & 22.26 & 392.00 & 39.06 \\
1989 & 0.00 & 8.00 & 28.00 & 482.50 & 48.83 \\
1990 & 0.10 & 13.00 & 44.13 & 644.60 & 78.74 \\
1991 & 0.10 & 16.00 & 61.77 & 953.60 & 114.11 \\
\hline Total & 0.00 & 5.40 & 22.49 & 953.60 & 48.89 \\
\hline
\end{tabular}

Table 4.10

Descriptive Statistics for Total KVA

\begin{tabular}{|c|c|c|c|c|c|}
\hline Year & Minimum & Median & Mean & Maximum & Std. Dev. \\
\hline 1985 & 0.00 & 14.00 & 40.01 & 570.00 & 58.01 \\
1986 & 0.00 & 21.20 & 52.77 & 476.40 & 71.88 \\
1987 & 0.00 & 13.10 & 45.01 & 566.70 & 72.03 \\
1988 & 0.00 & 23.30 & 50.68 & 632.00 & 72.19 \\
1989 & 0.00 & 23.10 & 54.61 & 805.40 & 83.23115 .96 \\
1990 & 0.00 & 29.60 & 71.23 & 905.70 & 128.98 \\
1991 & 0.00 & 35.60 & 79.90 & 1063.00 & \\
\hline Total & 0.00 & 21.00 & 52.81 & 1063.00 & 82.65 \\
\hline
\end{tabular}


Table 4.11

Descriptive Statistics for Age Young

\begin{tabular}{|c|c|c|c|c|c|}
\hline Year & Minimum & Median & Mean & Maximum & Std. Dev. \\
\hline 1985 & 0.00 & 3.00 & 3.62 & 21.00 & 2.91 \\
1986 & 0.00 & 3.00 & 3.79 & 21.00 & 3.04 \\
1987 & 0.00 & 3.00 & 3.62 & 21.00 & 2.82 \\
1988 & 0.00 & 3.00 & 3.35 & 23.00 & 2.72 \\
1989 & 0.00 & 3.00 & 3.43 & 28.00 & 2.70 \\
1990 & 0.00 & 3.00 & 3.59 & 26.00 & 2.57 \\
1991 & 0.00 & 3.00 & 4.03 & 18.00 & 2.66 \\
\hline Total & 0.00 & 3.00 & 3.58 & 28.00 & 2.80 \\
\hline
\end{tabular}

Table 4.12

Number of 0's and 1's in IBM Dummy Variable

\begin{tabular}{|c|c|c|}
\hline Year & 0 & 1 \\
\hline 1985 & 547 & 2392 \\
1986 & 696 & 2538 \\
1987 & 829 & 3380 \\
1988 & 1254 & 2421 \\
1989 & 1353 & 2296 \\
1990 & 918 & 1923 \\
1991 & 348 & 373 \\
\hline
\end{tabular}


Table 4.13

Definitions of the Instrumental Variables

\begin{tabular}{|l|l|}
\hline \multicolumn{1}{|c|}{ Variable } & \multicolumn{1}{c|}{ Definition } \\
\hline Time & $\begin{array}{c}\text { A dummy variable for the time period of observation. The variable } \\
\text { takes a 1 if the observation falls in the year, 0 otherwise. }\end{array}$ \\
\hline Region & $\begin{array}{l}\text { Dummy variables for the region of the country in which the site } \\
\text { resides. There are 9 regions: New England, Middle Atlantic, East } \\
\text { North Central, West North Central, South Atlantic, East South Central, } \\
\text { West South Central, Mountain and Pacific. }\end{array}$ \\
\hline SMSA & $\begin{array}{l}\text { This is a dummy variable that takes the value 1 if the site resides } \\
\text { inside an SMSA and a 0 otherwise. This variable is provided by CIC. }\end{array}$ \\
\hline $\begin{array}{l}\text { These are characteristics (minimum memory, maximum memory } \\
\text { and MIPS) of the closest neighbors to the system in characteristics } \\
\text { space. The distance measure used is Mahalanobis distance defined as } \\
\left(x_{0}-x_{i}\right)^{T} \sum^{-1}\left(x_{0}-x_{\dot{1}}\right)\end{array}$ \\
$\begin{array}{l}\text { where } x_{0} \text { are the characteristics of the system, } x_{i} \text { represents the } \\
\text { characteristics of all systems except } x_{0} \text { and } \sum \text { represents the } \\
\text { covariance matrix of the variables minimum memory, maximum } \\
\text { memory and MIPS. }\end{array}$ \\
\hline
\end{tabular}




\begin{tabular}{|c|c|c|c|c|}
\hline \multicolumn{5}{|c|}{$\begin{array}{l}\text { Table } 5.1 \\
\text { One Characteristic Model } \\
\text { Hedonic Surface Estimates }\end{array}$} \\
\hline Year & Coefficient & Value & Std. Error & $t$ value \\
\hline 1985 & $\begin{array}{l}\beta_{0} \\
\beta_{1} \\
\beta_{2}\end{array}$ & $\begin{array}{r}-265.53 \\
3503.73 \\
-45.87\end{array}$ & $\begin{array}{r}69.42 \\
20.59 \\
0.83\end{array}$ & $\begin{array}{r}-3.82 \\
170.19 \\
-54.96\end{array}$ \\
\hline 1986 & $\begin{array}{l}\beta_{0} \\
\beta_{1} \\
\beta_{2}\end{array}$ & $\begin{array}{r}-4.35 \\
3163.35 \\
-26.15\end{array}$ & $\begin{array}{r}106.83 \\
28.15 \\
1.03\end{array}$ & $\begin{array}{r}-0.04 \\
112.37 \\
-25.44\end{array}$ \\
\hline 1987 & $\begin{array}{l}\beta_{0} \\
\beta_{1} \\
\beta_{2}\end{array}$ & $\begin{array}{r}1373.90 \\
1809.72 \\
6.06\end{array}$ & $\begin{array}{r}155.29 \\
24.67 \\
0.56\end{array}$ & $\begin{array}{r}8.85 \\
73.36 \\
10.73\end{array}$ \\
\hline 1988 & $\begin{array}{l}\beta_{0} \\
\beta_{1} \\
\beta_{2} \\
\end{array}$ & $\begin{array}{r}673.00 \\
1667.63 \\
3.21 \\
\end{array}$ & $\begin{array}{r}194.72 \\
20.25 \\
0.30\end{array}$ & $\begin{array}{r}3.46 \\
82.37 \\
10.61 \\
\end{array}$ \\
\hline 1989 & $\begin{array}{l}\beta_{0} \\
\beta_{1} \\
\beta_{2}\end{array}$ & $\begin{array}{r}-2440.01 \\
1651.60 \\
-3.24\end{array}$ & $\begin{array}{r}176.70 \\
13.33 \\
0.14\end{array}$ & $\begin{array}{l}-13.81 \\
123.88 \\
-22.46\end{array}$ \\
\hline 1990 & $\begin{array}{l}\beta_{0} \\
\beta_{1} \\
\beta_{2}\end{array}$ & $\begin{array}{r}-1597.96 \\
1008.34 \\
-0.70\end{array}$ & $\begin{array}{r}200.87 \\
12.42 \\
0.12\end{array}$ & $\begin{array}{l}-7.96 \\
81.20 \\
-6.08\end{array}$ \\
\hline 1991 & $\begin{array}{l}\beta_{0} \\
\beta_{1} \\
\beta_{2}\end{array}$ & $\begin{array}{r}-775.02 \\
513.83 \\
1.61\end{array}$ & $\begin{array}{r}463.96 \\
25.82 \\
0.23\end{array}$ & $\begin{array}{r}-1.67 \\
19.90 \\
7.06\end{array}$ \\
\hline
\end{tabular}




\begin{tabular}{|l|r|r|r|}
\hline \multicolumn{4}{|c|}{ Table 5.2 } \\
\multicolumn{4}{|c|}{ One Characteristic Model } \\
\hline \multicolumn{1}{|c|}{ Variable } & \multicolumn{1}{|c|}{ Value } & Std. Error & \multicolumn{1}{c|}{ t value } \\
\hline$\alpha_{0}$ & 1971.65 & 60.89 & 32.38 \\
$\alpha_{1}$ & -12.82 & 0.49 & -26.28 \\
REFMAN & 29.22 & 67.17 & 0.43 \\
PUB & -27.61 & 77.34 & -0.36 \\
CHEM & -73.95 & 78.44 & -0.94 \\
FABMAN & 62.68 & 66.27 & 0.95 \\
COMP & 24.81 & 68.90 & 0.36 \\
ELEQUIP & 78.31 & 69.95 & 1.12 \\
TRANSP & 29.94 & 74.96 & 0.40 \\
UTIL & -43.34 & 75.06 & -0.58 \\
COMM & 47.52 & 75.07 & 0.63 \\
ELECTRIC & -25.29 & 73.24 & -0.35 \\
WHOLE & 103.37 & 72.14 & 1.43 \\
RETAII & -26.30 & 65.40 & -0.40 \\
FIN & 61.05 & 75.32 & 0.81 \\
DEPOSIT & 21.80 & 63.96 & 0.34 \\
CREDIT & 144.10 & 76.80 & 1.88 \\
INS & 57.23 & 64.40 & 0.89 \\
BUSSERV & -30.31 & 60.96 & -0.50 \\
SOCSERV & 45.24 & 80.11 & 0.56 \\
HEALTH & -20.69 & 67.88 & -0.30 \\
EDU & 4.27 & 66.79 & 0.06 \\
GOV & -30.55 & 67.07 & -0.46 \\
ADGOV & 46.63 & 68.57 & 0.68 \\
DEFENSE & 7.84 & 75.74 & 0.10 \\
Site Value & 0.05 & 0.00 & 11.23 \\
Max Mips & -9.34 & 0.82 & -11.37 \\
Total Mips & -2.69 & 0.47 & -5.75 \\
Total KVA & 0.75 & 0.20 & 3.73 \\
Age Young & 3.27 & 3.07 & 1.06 \\
IBM & 200.26 & 18.12 & 11.05 \\
\hline
\end{tabular}


Table 5.3A

One Characteristic Model Forward index Utility-Based Price Index- $P^{*}$ as Weight

\begin{tabular}{|c|c|c|c|c|c|c|}
\hline & 1985 & 1986 & 1987 & 1988 & 1989 & 1990 \\
\hline 1985 & 231.38 & & & & & \\
1986 & 267.69 & 234.22 & & & & \\
1987 & 196.32 & 193.97 & 226.93 & & & \\
1988 & 190.36 & 189.47 & 198.62 & 221.20 & & \\
1989 & 182.88 & 182.52 & 183.32 & 183.27 & 208.17 & \\
1990 & 135.47 & 135.36 & 135.58 & 136.17 & 136.79 & 187.32 \\
1991 & 100.00 & 100.00 & 100.00 & 100.00 & 100.00 & 100.00 \\
\hline AAGR & -13.98 & -17.02 & -20.49 & -26.46 & -36.66 & -62.76 \\
\hline
\end{tabular}

Table 5.3B

One Characteristic Model Forward index Utility-Based Price Index- $-P^{0}$ as Weight

\begin{tabular}{|c|c|c|c|c|c|c|}
\hline & 1985 & 1986 & 1987 & 1988 & 1989 & 1990 \\
\hline 1985 & 236.13 & & & & & \\
1986 & 259.12 & 241.54 & & & & \\
1987 & 188.39 & 184.15 & 231.06 & & & \\
1988 & 186.53 & 184.95 & 197.74 & 226.75 & & \\
1989 & 182.42 & 182.27 & 182.61 & 179.70 & 201.04 & \\
1990 & 135.14 & 134.99 & 135.23 & 135.56 & 136.76 & 161.50 \\
1991 & 100.00 & 100.00 & 100.00 & 100.00 & 100.00 & 100.00 \\
\hline AAGR & -14.32 & -17.64 & -20.94 & -27.29 & -34.92 & -47.93 \\
\hline
\end{tabular}




\begin{tabular}{|c|r|r|}
\hline \multicolumn{3}{|c|}{ Table 5.4 } \\
One Characteristic Model \\
Traditional Hedonic Indexes \\
\hline Year & Log-Log & Log-Linear \\
\hline 1985 & 706.29 & 571.66 \\
1986 & 666.91 & 651.22 \\
1987 & 465.21 & 513.50 \\
1988 & 383.74 & 455.22 \\
1989 & 266.21 & 307.81 \\
1990 & 179.84 & 195.30 \\
1991 & 100.00 & 100.00 \\
\hline AAGR & -32.58 & -29.06 \\
\hline
\end{tabular}

\begin{tabular}{|c|r|r|}
\hline \multicolumn{3}{|c|}{ Table 5.5 } \\
One Characteristic Model \\
Forward Linked Indexes \\
\hline Year & $P^{*}$ as Weight & $P^{0}$ as Weight \\
\hline 1985 & 410.29 & 418.40 \\
1986 & 474.68 & 459.14 \\
1987 & 393.11 & 350.05 \\
1988 & 344.07 & 299.57 \\
1989 & 285.07 & 237.41 \\
1990 & 187.32 & 161.50 \\
1991 & 100.00 & 100.00 \\
\hline AAGR & -23.53 & -23.85 \\
\hline
\end{tabular}




\begin{tabular}{|c|c|c|c|c|c|c|}
\hline \multicolumn{7}{|c|}{$\begin{array}{c}\text { Table } 5.6 \\
\text { One Characteristic Model } \\
\text { Reverse Index }\end{array}$} \\
\hline & 1986 & 1987 & 1988 & 1989 & 1990 & 1991 \\
\hline $\begin{array}{l}1985 \\
1986 \\
1987 \\
1988 \\
1989 \\
1990 \\
1991 \\
\end{array}$ & $\begin{array}{r}100.00 \\
78.15\end{array}$ & $\begin{array}{r}100.00 \\
104.61 \\
64.30\end{array}$ & $\begin{array}{r}100.00 \\
104.81 \\
68.75 \\
67.81\end{array}$ & $\begin{array}{r}100.00 \\
104.45 \\
75.02 \\
68.11 \\
59.78\end{array}$ & $\begin{array}{r}100.00 \\
104.89 \\
76.83 \\
71.47 \\
57.31 \\
45.33\end{array}$ & $\begin{array}{r}100.00 \\
106.79 \\
73.75 \\
69.82 \\
57.65 \\
38.00 \\
34.63\end{array}$ \\
\hline AAGR & -24.65 & -22.08 & -12.95 & -12.86 & -15.82 & -17.67 \\
\hline
\end{tabular}

Table 5.7

One Characteristic Model

Reverse Linked Index

\begin{tabular}{|c|r|}
\hline Year & \multicolumn{1}{|c|}{$P^{0}$ as Weight } \\
\hline 1985 & 100.00 \\
1986 & 78.15 \\
1987 & 48.04 \\
1988 & 47.38 \\
1989 & 41.59 \\
1990 & 32.90 \\
1991 & 29.98 \\
\hline AAGR & -20.08 \\
\hline
\end{tabular}




\begin{tabular}{|c|c|c|c|c|c|c|}
\hline \multicolumn{7}{|c|}{ Table 5.8A } \\
One Characteristic Forward Index \\
Utility-Based Index- $P$-IBM Only \\
\hline & 1985 & 1986 & 1987 & 1988 & 1989 & 1990 \\
\hline 1985 & 233.29 & & & & & \\
1986 & 266.68 & 236.75 & & & & \\
1987 & 195.09 & 192.37 & 227.82 & & & \\
1988 & 190.65 & 189.68 & 199.31 & 221.70 & & \\
1989 & 183.58 & 183.49 & 184.08 & 183.72 & 207.76 & \\
1990 & 134.04 & 133.96 & 134.26 & 134.93 & 135.59 & 184.59 \\
1991 & 100.00 & 100.00 & 100.00 & 100.00 & 100.00 & 100.00 \\
\hline AAGR & -14.12 & -17.24 & -20.59 & -26.54 & -36.56 & -61.30 \\
\hline
\end{tabular}

\begin{tabular}{|c|c|c|c|c|c|c|}
\hline \multicolumn{7}{|c|}{ Table 5.8B } \\
One Characteristic Forward Index \\
Utility-Based Index-P - IBM Only \\
\hline & 1985 & 1986 & 1987 & 1988 & 1989 & 1990 \\
\hline 1985 & 238.26 & & & & & \\
1986 & 259.91 & 243.86 & & & & \\
1987 & 185.88 & 181.25 & 232.35 & & & \\
1988 & 187.35 & 185.23 & 198.15 & 227.27 & & \\
1989 & 183.03 & 182.93 & 183.35 & 177.83 & 200.77 & \\
1990 & 133.84 & 133.77 & 134.11 & 134.60 & 135.78 & 158.70 \\
1991 & 100.00 & 100.00 & 100.00 & 100.00 & 100.00 & 100.00 \\
\hline AAGR & -14.47 & -17.83 & -21.08 & -27.37 & -34.85 & -46.19 \\
\hline
\end{tabular}




\begin{tabular}{|c|r|r|}
\hline \multicolumn{3}{|c|}{ Table 5.9 } \\
\multicolumn{3}{|c|}{ One Characteristic Model } \\
\hline Traditional Hedonic Indexes-IBM Only \\
\hline Year & Log-Log & Log-Linear \\
\hline 1985 & 735.16 & 552.83 \\
1986 & 682.01 & 664.28 \\
1987 & 453.40 & 487.97 \\
1988 & 389.19 & 448.92 \\
1989 & 270.50 & 308.01 \\
1990 & 177.69 & 191.04 \\
1991 & 100.00 & 100.00 \\
\hline AAGR & -33.25 & -28.50 \\
\hline
\end{tabular}

\begin{tabular}{|c|r|r|}
\hline \multicolumn{3}{|c|}{ Table 5.10 } \\
One Characteristic Forward Index \\
Linked Indexes-IBM Only \\
\hline Year & $P^{*}$ as Weight & $P^{0}$ as Weight \\
\hline 1985 & 420.01 & 433.73 \\
1986 & 480.13 & 473.14 \\
1987 & 390.13 & 351.66 \\
1988 & 341.31 & 299.90 \\
1989 & 282.84 & 234.66 \\
1990 & 184.59 & 158.70 \\
1991 & 100.00 & 100.00 \\
\hline AAGR & -23.92 & -24.45 \\
\hline
\end{tabular}




\begin{tabular}{|c|r|r|r|r|r|r|}
\hline \multicolumn{7}{|c|}{$\begin{array}{c}\text { Table 5.11 } \\
\text { One Characteristic } \\
\text { Reverse Index-IBM Only }\end{array}$} \\
\hline & 1986 & 1987 & \multicolumn{1}{|c|}{1988} & 1989 & 1990 & 1991 \\
\hline 1985 & 100.00 & 100.00 & 100.00 & 100.00 & 100.00 & 100.00 \\
1986 & 81.92 & 106.29 & 106.99 & 106.59 & 106.75 & 109.26 \\
1987 & & 65.18 & 69.84 & 75.93 & 78.05 & 74.86 \\
1988 & & & 69.02 & 69.44 & 73.05 & 71.52 \\
1989 & & & & 60.90 & 58.97 & 60.02 \\
1990 & & & & & 45.41 & 39.55 \\
1991 & & & & & & 35.25 \\
\hline AAGR & -19.94 & -21.40 & -12.36 & -12.40 & -15.79 & -17.38 \\
\hline
\end{tabular}

Table 5.12

One Characteristic Model Reverse Linked Index-IBM Only

\begin{tabular}{|c|r|}
\hline Year & \multicolumn{1}{|c|}{$P^{0}$ as Weight } \\
\hline 1985 & 100.00 \\
1986 & 81.92 \\
1987 & 50.24 \\
1988 & 49.65 \\
1989 & 43.54 \\
1990 & 33.53 \\
1991 & 29.88 \\
\hline AAGR & -20.13 \\
\hline
\end{tabular}




\begin{tabular}{|c|c|c|c|c|}
\hline \multicolumn{5}{|c|}{$\begin{array}{l}\text { Table } 5.13 \\
\text { Three Characteristic Model } \\
\text { Hedonic Surface Estimates }\end{array}$} \\
\hline Year & Coefficient & Value & Std. Error & $\mathrm{t}$ value \\
\hline 1985 & $\begin{array}{l}\beta_{0} \\
\beta_{1} \\
\beta_{2} \\
\beta_{3} \\
\beta_{4} \\
\beta_{5} \\
\beta_{6} \\
\end{array}$ & $\begin{array}{r}-354.39 \\
378.22 \\
3158.82 \\
-18.49 \\
-6.68 \\
-35.89 \\
-0.02 \\
\end{array}$ & $\begin{array}{r}91.53 \\
43.34 \\
54.46 \\
5.50 \\
1.46 \\
2.38 \\
0.02 \\
\end{array}$ & $\begin{array}{r}-3.87 \\
8.73 \\
58.00 \\
-3.36 \\
-4.57 \\
-15.11 \\
-0.98 \\
\end{array}$ \\
\hline 1986 & $\begin{array}{l}\beta_{0} \\
\beta_{1} \\
\beta_{2} \\
\beta_{3} \\
\beta_{4} \\
\beta_{5} \\
\beta_{6} \\
\end{array}$ & $\begin{array}{r}-363.90 \\
-23.91 \\
3418.26 \\
0.74 \\
3.91 \\
-49.46 \\
-0.03 \\
\end{array}$ & $\begin{array}{r}96.53 \\
26.47 \\
34.14 \\
5.68 \\
0.35 \\
0.99 \\
0.02 \\
\end{array}$ & $\begin{array}{r}-3.77 \\
-0.90 \\
100.12 \\
0.13 \\
11.11 \\
-49.73 \\
-1.58\end{array}$ \\
\hline 1987 & $\begin{array}{l}\beta_{0} \\
\beta_{1} \\
\beta_{2} \\
\beta_{3} \\
\beta_{4} \\
\beta_{5} \\
\beta_{6} \\
\end{array}$ & $\begin{array}{r}-503.91 \\
406.79 \\
618.03 \\
116.94 \\
-0.89 \\
6.00 \\
-0.13 \\
\end{array}$ & $\begin{array}{r}92.97 \\
19.15 \\
31.39 \\
5.00 \\
0.25 \\
0.82 \\
0.01 \\
\end{array}$ & $\begin{array}{r}-5.42 \\
21.24 \\
19.69 \\
23.29 \\
-3.63 \\
7.36 \\
-8.97 \\
\end{array}$ \\
\hline 1988 & $\begin{array}{l}\beta_{0} \\
\beta_{1} \\
\beta_{2} \\
\beta_{3} \\
\beta_{4} \\
\beta_{5} \\
\beta_{6} \\
\end{array}$ & $\begin{array}{r}-295.86 \\
466.20 \\
882.19 \\
2.35 \\
-0.91 \\
4.54 \\
0.00 \\
\end{array}$ & $\begin{array}{r}179.06 \\
19.51 \\
31.24 \\
1.13 \\
0.13 \\
0.40 \\
0.00 \\
\end{array}$ & $\begin{array}{r}-1.65 \\
23.89 \\
28.24 \\
2.08 \\
-7.26 \\
11.25 \\
-0.65 \\
\end{array}$ \\
\hline
\end{tabular}




\begin{tabular}{|c|r|r|r|r|}
\hline \multicolumn{5}{|c|}{ Table 5.13 (Cont.) } \\
\hline Year & Coefficient & \multicolumn{1}{c|}{ Value } & \multicolumn{1}{c|}{ Std. Error } & t value \\
\hline \multirow{4}{*}{1989} & $\beta_{0}$ & -2688.73 & 192.69 & -13.95 \\
& $\beta_{1}$ & 300.19 & 20.16 & 14.89 \\
& $\beta_{2}$ & 902.15 & 27.41 & 32.91 \\
& $\beta_{3}$ & 14.02 & 1.00 & 13.95 \\
& $\beta_{4}$ & -0.82 & 0.10 & -8.24 \\
& $\beta_{5}$ & 2.06 & 0.24 & 8.61 \\
& $\beta_{6}$ & -0.01 & 0.00 & -14.67 \\
\hline & $\beta_{0}$ & -2737.45 & 231.89 & -11.80 \\
& $\beta_{1}$ & 210.36 & 20.16 & 10.43 \\
& $\beta_{2}$ & 768.65 & 28.03 & 27.42 \\
& $\beta_{3}$ & -0.29 & 0.51 & -0.56 \\
& $\beta_{4}$ & -0.93 & 0.10 & -9.32 \\
& $\beta_{5}$ & 0.08 & 0.20 & 0.41 \\
& $\beta_{6}$ & 0.00 & 0.00 & 4.58 \\
\hline \multirow{5}{*}{1990} & $\beta_{0}$ & -1204.85 & 509.82 & -2.36 \\
& $\beta_{1}$ & 60.22 & 38.54 & 1.56 \\
& $\beta_{2}$ & 456.06 & 55.55 & 8.21 \\
& $\beta_{3}$ & 0.33 & 0.87 & 0.37 \\
& $\beta_{4}$ & -0.33 & 0.17 & -1.98 \\
& $\beta_{5}$ & 1.25 & 0.37 & 3.39 \\
& & 0.00 & 0.00 & 2.50 \\
\hline
\end{tabular}

Table 5.14

Correlation Matrix for

Computer Characteristics

\begin{tabular}{|c|c|c|c|}
\hline & Min & Mips & Max \\
\hline Min & 1.00 & 0.92 & 0.76 \\
\hline Mips & 0.92 & 1.00 & 0.86 \\
\hline Max & 0.76 & 0.86 & 1.00 \\
\hline
\end{tabular}


Table 5.15

Three Characteristic Model Minimum Memory Demand

\begin{tabular}{|l|r|r|r|}
\hline \multicolumn{1}{|c|}{ Variable } & \multicolumn{1}{c|}{ Value } & \multicolumn{1}{c|}{ Std. Error } & \multicolumn{1}{c|}{$\mathrm{t}$ value } \\
\hline$\alpha_{10}$ & 346.25 & 13.54 & 25.58 \\
$\alpha_{11}$ & -1.35 & 0.06 & -21.64 \\
REFMAN & -34.95 & 14.66 & -2.38 \\
PUB & -48.38 & 17.23 & -2.81 \\
CHEM & -27.29 & 17.02 & -1.60 \\
FABMAN & -32.43 & 14.88 & -2.18 \\
COMP & -38.58 & 15.38 & -2.51 \\
ELEQUP & -28.82 & 15.16 & -1.90 \\
TRANSP & -13.84 & 16.70 & -0.83 \\
UTIL & -24.28 & 16.54 & -1.47 \\
COMM & -16.20 & 16.73 & -0.97 \\
ELECTRIC & -39.42 & 16.40 & -2.40 \\
WHOLE & -34.21 & 16.18 & -2.11 \\
RETAIL & -34.39 & 14.38 & -2.39 \\
FIN & -28.12 & 16.42 & -1.71 \\
DEPOSIT & -38.28 & 14.17 & -2.70 \\
CREDIT & -22.55 & 17.32 & -1.30 \\
NNS & -22.50 & 14.21 & -1.58 \\
BUSSERV & -21.07 & 13.44 & -1.57 \\
SOCSERV & -48.66 & 17.20 & -2.83 \\
HEALTH & -27.43 & 14.94 & -1.84 \\
EDU & -37.30 & 14.55 & -2.56 \\
GOV & -21.39 & 14.59 & -1.47 \\
ADGOV & -34.09 & 15.07 & -2.26 \\
DEFENSE & -31.56 & 16.34 & -1.93 \\
Site Value & 0.00 & 0.00 & 3.96 \\
Max MIPS & -0.73 & 0.19 & -3.86 \\
Total MIPS & -0.39 & 0.11 & -3.55 \\
Total KVA & 0.04 & 0.04 & 1.01 \\
Age Young & -4.37 & 0.67 & -6.48 \\
IBM & -3.24 & 3.94 & -0.82 \\
\hline
\end{tabular}




\begin{tabular}{|l|r|r|r|}
\hline \multicolumn{4}{|c|}{ Table 5.16 } \\
\hline \multicolumn{4}{|c|}{ Mree Characteristic Model } \\
\hline \multicolumn{1}{|c|}{ Variable } & \multicolumn{1}{|c|}{ Value } & \multicolumn{1}{c|}{ Std. Error } & t value \\
\hline$\alpha_{20}$ & 1196.10 & 84.09 & 14.22 \\
$\alpha_{21}$ & -7.63 & 0.67 & -11.38 \\
REFMAN & 187.77 & 91.11 & 2.06 \\
PUB & 120.53 & 107.11 & 1.13 \\
CHEM & 120.27 & 105.84 & 1.14 \\
FABMAN & 263.45 & 92.49 & 2.85 \\
COMP & 133.22 & 95.61 & 1.39 \\
ELEQUIP & 218.16 & 94.26 & 2.31 \\
TRANSP & 64.77 & 103.85 & 0.62 \\
UTU & 38.17 & 102.79 & 0.37 \\
COMM & 168.00 & 103.99 & 1.62 \\
ELECTRIC & 114.44 & 101.95 & 1.12 \\
WHOLE & 307.18 & 100.57 & 3.05 \\
RETAIL & 108.04 & 89.40 & 1.21 \\
FIN & 147.70 & 102.06 & 1.45 \\
DEPOSIT & 157.17 & 88.07 & 1.78 \\
CREDIT & 163.37 & 107.66 & 1.52 \\
INS & 194.33 & 88.35 & 2.20 \\
BUSSERV & 96.90 & 83.58 & 1.16 \\
SOCSERV & 62.72 & 106.91 & 0.59 \\
HEALTH & 82.09 & 92.90 & 0.88 \\
EDU & 182.94 & 90.42 & 2.02 \\
GOV & 15.17 & 90.73 & 0.17 \\
ADGOV & 188.71 & 93.69 & 2.01 \\
DEFENSE & 139.46 & 101.55 & 1.37 \\
Site Value & 0.03 & 0.01 & 4.54 \\
Max MIPS & -7.79 & 1.20 & -6.49 \\
Total MIPS & -1.76 & 0.69 & -2.56 \\
Total KVA & 0.95 & 0.27 & 3.50 \\
Age Young & 13.34 & 4.20 & 3.18 \\
IBM & 188.26 & 24.49 & 7.69 \\
\hline
\end{tabular}




\begin{tabular}{|l|r|r|r|}
\hline \multicolumn{4}{|c|}{ Table 5.17 } \\
\multicolumn{4}{|c|}{ Three Characteristic Model } \\
\hline \multicolumn{1}{|c|}{ Variable } & Value & Std. Error & t value \\
\hline$\alpha_{20}$ & 19.47 & 3.91 & 4.98 \\
$\alpha_{21}$ & -0.01 & 0.00 & -7.52 \\
REFMAN & 3.42 & 4.23 & 0.81 \\
PUB & 3.03 & 4.98 & 0.61 \\
CHEM & 5.69 & 4.92 & 1.16 \\
FABMAN & -0.07 & 4.30 & -0.02 \\
COMP & -2.56 & 4.44 & -0.58 \\
ELEQUIP & -2.88 & 4.38 & -0.66 \\
TRANSP & -3.79 & 4.83 & -0.79 \\
UTIL & 2.07 & 4.78 & 0.43 \\
COMM & -2.22 & 4.83 & -0.46 \\
ELECTRIC & -2.23 & 4.74 & -0.47 \\
WHOLE & -0.64 & 4.67 & -0.14 \\
RETAIL & 0.91 & 4.16 & 0.22 \\
FIN & -0.12 & 4.75 & -0.03 \\
DEPOSIT & -0.20 & 4.09 & -0.05 \\
CREDIT & 4.14 & 5.00 & 0.83 \\
INS & 0.07 & 4.11 & 0.02 \\
BUSSERV & 0.78 & 3.88 & 0.20 \\
SOCSERV & -0.71 & 4.97 & -0.14 \\
HEALTH & 0.88 & 4.32 & 0.20 \\
EDU & 1.36 & 4.20 & 0.32 \\
GOV & 3.17 & 4.22 & 0.75 \\
ADGOV & -3.72 & 4.35 & -0.85 \\
DEFENSE & 1.66 & 4.72 & 0.35 \\
Site Value & 0.00 & 0.00 & 0.83 \\
Max MIPS & -0.24 & 0.05 & -4.38 \\
Total MIPS & 0.09 & 0.03 & 2.93 \\
Total KVA & -0.06 & 0.01 & -4.47 \\
Age Young & 0.00 & 0.20 & 0.01 \\
IBM & 4.55 & 1.14 & 4.00 \\
\hline
\end{tabular}




\begin{tabular}{|c|c|c|c|c|c|c|}
\hline \multicolumn{7}{|c|}{ Table 5.18A } \\
Utility-Based Price Index- $P^{*}$ as Weight \\
\hline & 1985 & 1986 & 1987 & 1988 & 1989 & 1990 \\
\hline 1985 & 326.20 & & & & & \\
1986 & 389.39 & 325.63 & & & & \\
1987 & 326.22 & 325.50 & 321.46 & & & \\
1988 & 252.06 & 253.80 & 259.36 & 310.94 & & \\
1989 & 228.80 & 228.35 & 239.50 & 247.74 & 297.24 & \\
1990 & 163.17 & 163.51 & 165.41 & 168.20 & 170.86 & 272.94 \\
1991 & 100.00 & 100.00 & 100.00 & 100.00 & 100.00 & 100.00 \\
\hline AAGR & -19.71 & -23.61 & -29.19 & -37.81 & -54.47 & -100.41 \\
\hline
\end{tabular}

\begin{tabular}{|c|c|c|c|c|c|c|}
\hline \multicolumn{7}{|c|}{ Table 5.18B } \\
Three Characteristic Model Forward Index \\
Utility-Based Price Index - $P^{0}$ as Weight \\
\hline & 1985 & 1986 & 1987 & 1988 & 1989 & 1990 \\
\hline 1985 & 329.80 & & & & & \\
1986 & 362.52 & 328.73 & & & & \\
1987 & 318.82 & 318.47 & 323.84 & & & \\
1988 & 253.60 & 255.44 & 268.21 & 306.48 & & \\
1989 & 218.95 & 219.70 & 236.62 & 249.78 & 280.36 & \\
1990 & 164.87 & 165.30 & 169.71 & 170.74 & 177.73 & 237.34 \\
1991 & 100.00 & 100.00 & 100.00 & 100.00 & 100.00 & 100.00 \\
\hline AAGR & -19.89 & -23.80 & -29.38 & -37.33 & -51.55 & -86.43 \\
\hline
\end{tabular}




\begin{tabular}{|c|r|r|}
\hline \multicolumn{3}{|c|}{ Table 5.19 } \\
Three Characteristic Model \\
Traditional Hedonic Indexes \\
\hline Year & Log-Log & Log-Linear \\
\hline 1985 & 863.50 & 484.86 \\
1986 & 790.98 & 513.64 \\
1987 & 532.31 & 388.36 \\
1988 & 416.19 & 343.03 \\
1989 & 284.22 & 225.12 \\
1990 & 189.24 & 164.45 \\
1991 & 100.00 & 100.00 \\
\hline AAGR & -35.93 & -26.31 \\
\hline
\end{tabular}

Table 5.20

Three Characteristic Model Forward Linked Index

\begin{tabular}{|c|r|r|}
\hline Year & $P^{*}$ as Weight & \multicolumn{1}{c|}{$P^{0}$ as Weight } \\
\hline 1985 & 619.03 & 520.86 \\
1986 & 738.95 & 572.53 \\
1987 & 738.65 & 554.66 \\
1988 & 595.96 & 459.38 \\
1989 & 474.83 & 374.39 \\
1990 & 272.94 & 237.34 \\
1991 & 100.00 & 100.00 \\
\hline AAGR & -30.38 & -27.51 \\
\hline
\end{tabular}




\begin{tabular}{|c|r|r|r|r|r|c|}
\hline \multicolumn{7}{|c|}{ Table 5.21 } \\
Three Characteristic Model \\
Reverse Index \\
\hline & \multicolumn{1}{|c|}{1986} & \multicolumn{1}{|c|}{1987} & \multicolumn{1}{|c|}{1988} & \multicolumn{1}{c|}{1989} & 1990 & 1991 \\
\hline 1985 & 100.00 & 100.00 & 100.00 & 100.00 & 100.00 & 100.00 \\
1986 & 59.35 & 82.53 & 86.52 & 88.70 & 90.02 & 90.53 \\
1987 & & 49.03 & 74.77 & 81.00 & 85.51 & 88.60 \\
1988 & & & 53.14 & 53.68 & 59.30 & 62.65 \\
1989 & & & & 48.78 & 53.94 & 57.07 \\
1990 & & & & & 38.88 & 30.68 \\
1991 & & & & & & 29.01 \\
\hline AAGR & -52.18 & -35.63 & -21.07 & -17.95 & -18.90 & -20.62 \\
\hline
\end{tabular}

\begin{tabular}{|c|r|}
\hline \multicolumn{2}{|c|}{ Table 5.22 } \\
Three Characteristic Model \\
Reverse Linked Index \\
\hline Year & \multicolumn{1}{|c|}{$P^{0}$ as Weight } \\
\hline 1985 & 100.00 \\
1986 & 59.35 \\
1987 & 35.26 \\
1988 & 25.06 \\
1989 & 22.77 \\
1990 & 16.41 \\
1991 & 15.52 \\
\hline AAGR & -31.05 \\
\hline
\end{tabular}




\begin{tabular}{|c|r|}
\hline \multicolumn{2}{|c|}{$\begin{array}{c}\text { Table } 5.23 \\
\text { Three Characteristic Model } \\
\text { Linked Index-Average All Growth Rates }\end{array}$} \\
\hline Year & $P^{*}$ as Weight \\
\hline 1985 & 362.06 \\
1986 & 432.21 \\
1987 & 395.52 \\
1988 & 310.97 \\
1989 & 273.77 \\
1990 & 184.14 \\
1991 & 100.00 \\
\hline AAGR & -21.44 \\
\hline
\end{tabular}

\begin{tabular}{|c|c|c|c|c|c|c|}
\hline \multicolumn{7}{|c|}{ Table 5.24A } \\
Three Characteristic Model Forward Index \\
\hline & 1985 & 1986 & 1987 & 1988 & 1989 & 1990 \\
\hline 1985 & 679.27 & & & & & \\
1986 & 721.05 & 674.56 & & & & \\
1987 & 722.03 & 706.41 & 670.03 & & & \\
1988 & 647.19 & 633.42 & 671.20 & 792.41 & & \\
1989 & 541.55 & 529.78 & 553.00 & 674.84 & 830.92 & \\
1990 & 302.42 & 297.81 & 307.65 & 363.71 & 404.07 & 812.54 \\
1991 & 100.00 & 100.00 & 100.00 & 100.00 & 100.00 & 100.00 \\
\hline AAGR & -31.93 & -38.18 & -47.55 & -69.00 & -105.87 & -209.50 \\
\hline
\end{tabular}




\begin{tabular}{|c|c|c|c|c|c|c|}
\hline \multicolumn{7}{|c|}{ Table 5.24B } \\
Three Characteristic Model Forward Index \\
\hline & 1985 & 1986 & 1987 & 1988 & 1989 & 1990 \\
\hline 1985 & 715.29 & & & & & \\
1986 & 707.64 & 704.08 & & & & \\
1987 & 727.45 & 707.00 & 702.53 & & & \\
1988 & 652.46 & 634.63 & 681.98 & 834.36 & & \\
1989 & 547.65 & 538.72 & 570.85 & 687.23 & 900.56 & \\
1990 & 306.00 & 299.67 & 312.18 & 365.76 & 434.23 & 1082.36 \\
1991 & 100.00 & 100.00 & 100.00 & 100.00 & 100.00 & 100.00 \\
\hline AAGR & -32.79 & -39.03 & -48.74 & -70.72 & -109.89 & -238.17 \\
\hline
\end{tabular}

Table 5.25

Three Characteristic Model Traditional Hedonic Indexes-IBM Only

\begin{tabular}{|c|r|r|}
\hline Year & \multicolumn{1}{|c|}{ Log-Log } & \multicolumn{1}{c|}{ Log-Linear } \\
\hline 1985 & 886.58 & 450.60 \\
1986 & 802.46 & 497.35 \\
1987 & 507.14 & 350.64 \\
1988 & 409.48 & 319.71 \\
1989 & 283.20 & 213.66 \\
1990 & 185.19 & 156.10 \\
1991 & 100.00 & 100.00 \\
\hline AAGR & -36.37 & -25.09 \\
\hline
\end{tabular}




\begin{tabular}{|c|r|r|}
\hline \multicolumn{3}{|c|}{ Table 5.26 } \\
Three Characteristic Model \\
\hline Linked Index-IBM Only \\
\hline Year & $P^{*}$ as Weight & \multicolumn{1}{|c|}{$P^{0}$ as Weight } \\
\hline 1985 & 1761.89 & 2826.07 \\
1986 & 1870.26 & 2795.84 \\
1987 & 1958.57 & 2807.43 \\
1988 & 1961.99 & 2725.31 \\
1989 & 1670.89 & 2244.73 \\
1990 & 812.54 & 1082.36 \\
1991 & 100.00 & 100.00 \\
\hline AAGR & -47.82 & -55.69 \\
\hline
\end{tabular}

\begin{tabular}{|c|r|r|r|r|r|r|}
\hline \multicolumn{7}{|c|}{ Table 5.27 } \\
Reverse Index IBM Only \\
\hline & 1986 & 1987 & 1988 & 1989 & 1990 & \multicolumn{1}{c|}{1991} \\
\hline 1985 & 100.00 & 100.00 & 100.00 & 100.00 & 100.00 & 100.00 \\
1986 & 79.30 & 87.79 & 91.50 & 93.50 & 95.07 & 95.92 \\
1987 & & 62.29 & 97.23 & 98.95 & 100.71 & 102.49 \\
1988 & & & 65.55 & 80.29 & 83.42 & 84.88 \\
1989 & & & & 58.08 & 62.79 & 64.17 \\
1990 & & & & & 43.89 & 26.94 \\
1991 & & & & & & 33.35 \\
\hline AAGR & -23.20 & -23.67 & -14.08 & -13.58 & -16.47 & -18.30 \\
\hline
\end{tabular}




\begin{tabular}{|c|r|}
\hline \multicolumn{2}{|c|}{ Table 5.28 } \\
Three Characteristic Model \\
Reverse Linked Index-IBM Only \\
\hline Year & $P^{0}$ as Weight \\
\hline 1985 & 100.00 \\
1986 & 79.30 \\
1987 & 56.27 \\
1988 & 37.94 \\
1989 & 27.44 \\
1990 & 19.18 \\
1991 & 23.74 \\
\hline AAGR & -23.97 \\
\hline
\end{tabular}

Table 5.29

Three Characteristic Model Linked Index-Average All Growth Rates-IBM Only

\begin{tabular}{|c|rc|}
\hline Year & \multicolumn{2}{|c|}{$P^{*}$ as Weight } \\
\hline 1985 & & 844.93 \\
1986 & & 896.91 \\
1987 & & 918.51 \\
1988 & & 854.45 \\
1989 & & 715.27 \\
1990 & & 386.01 \\
1991 & & 100.00 \\
\hline AAGR & & -35.57 \\
\hline
\end{tabular}


Figure 3.1

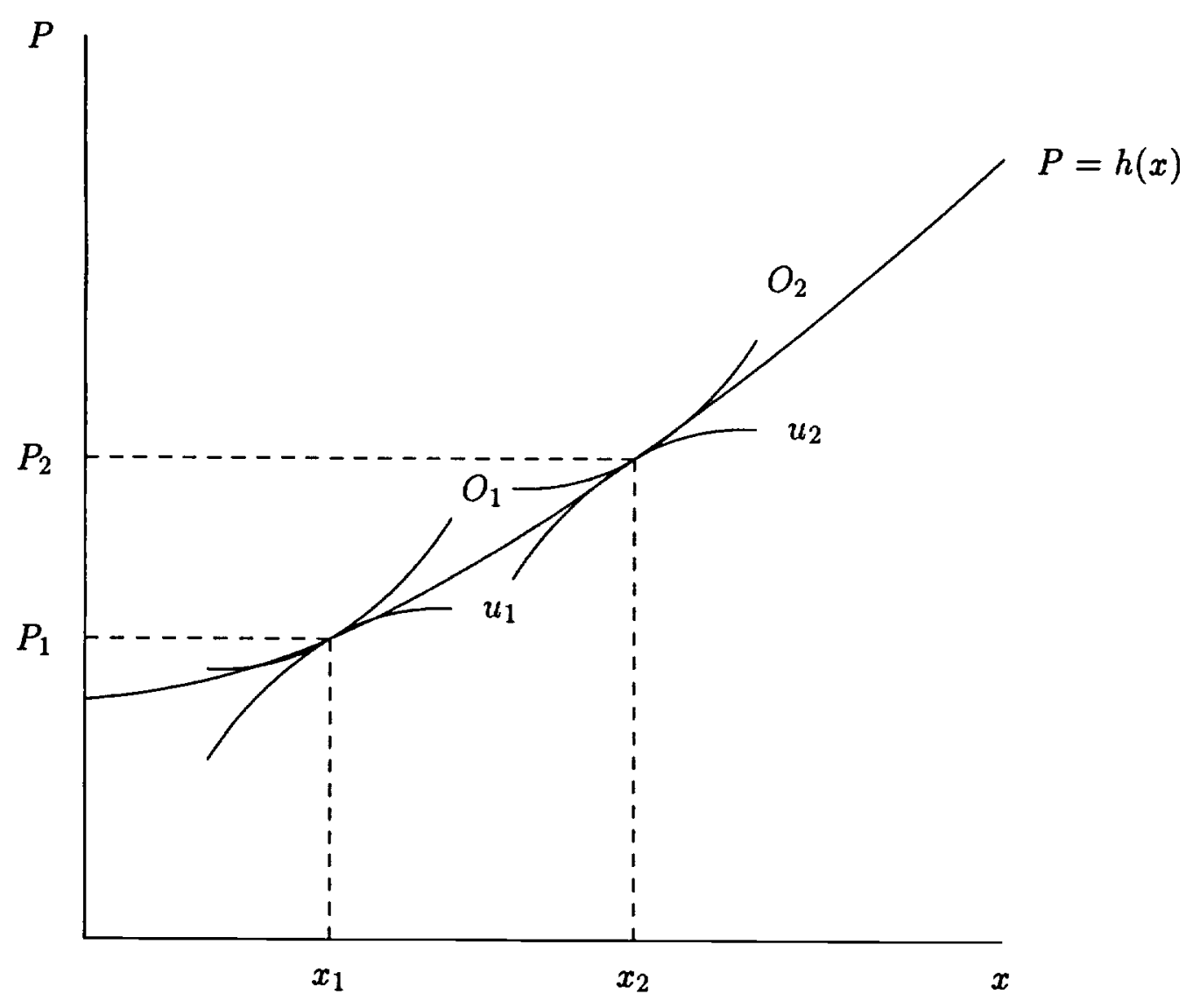


Figure 3.2

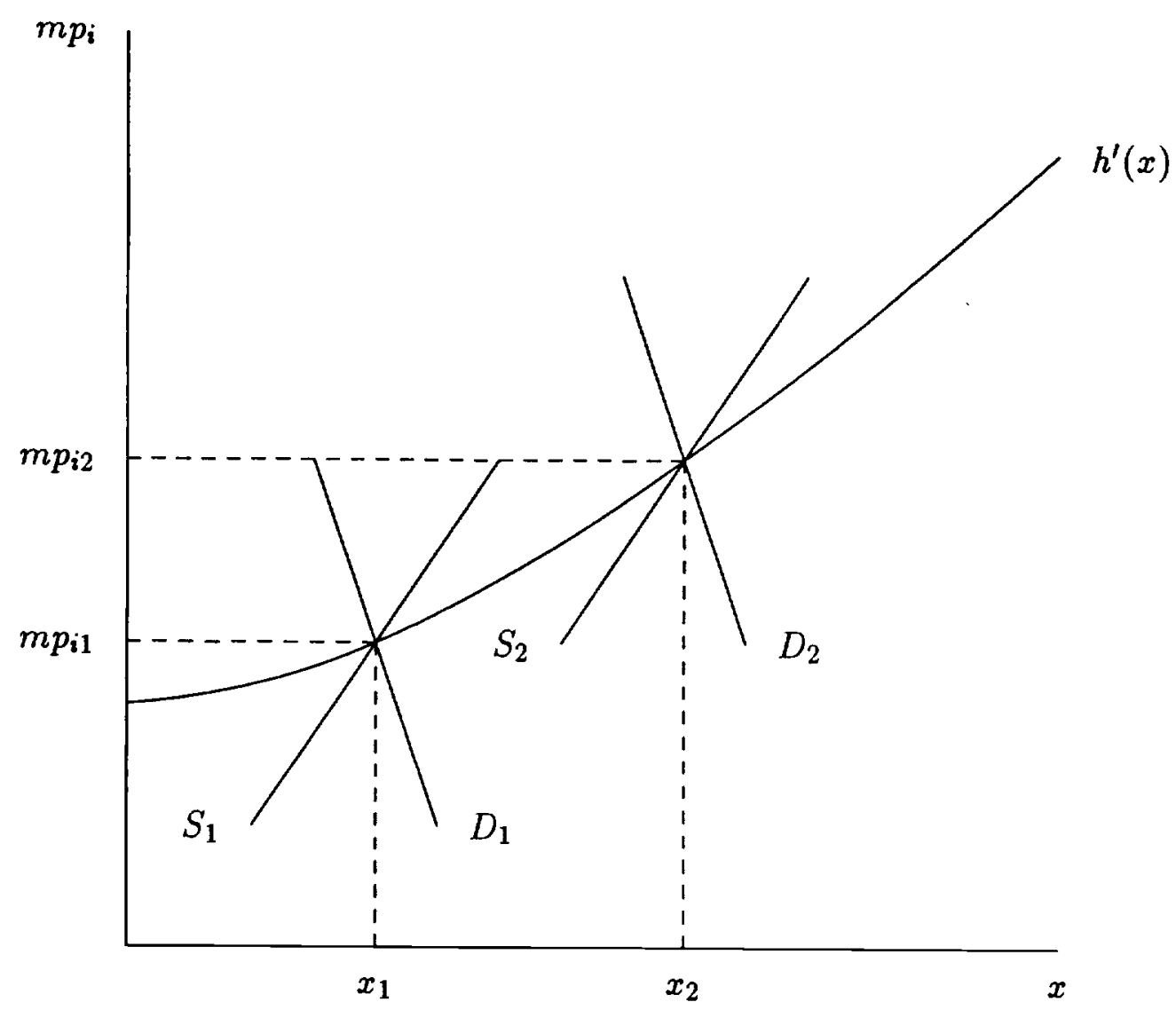


Figure 3.3

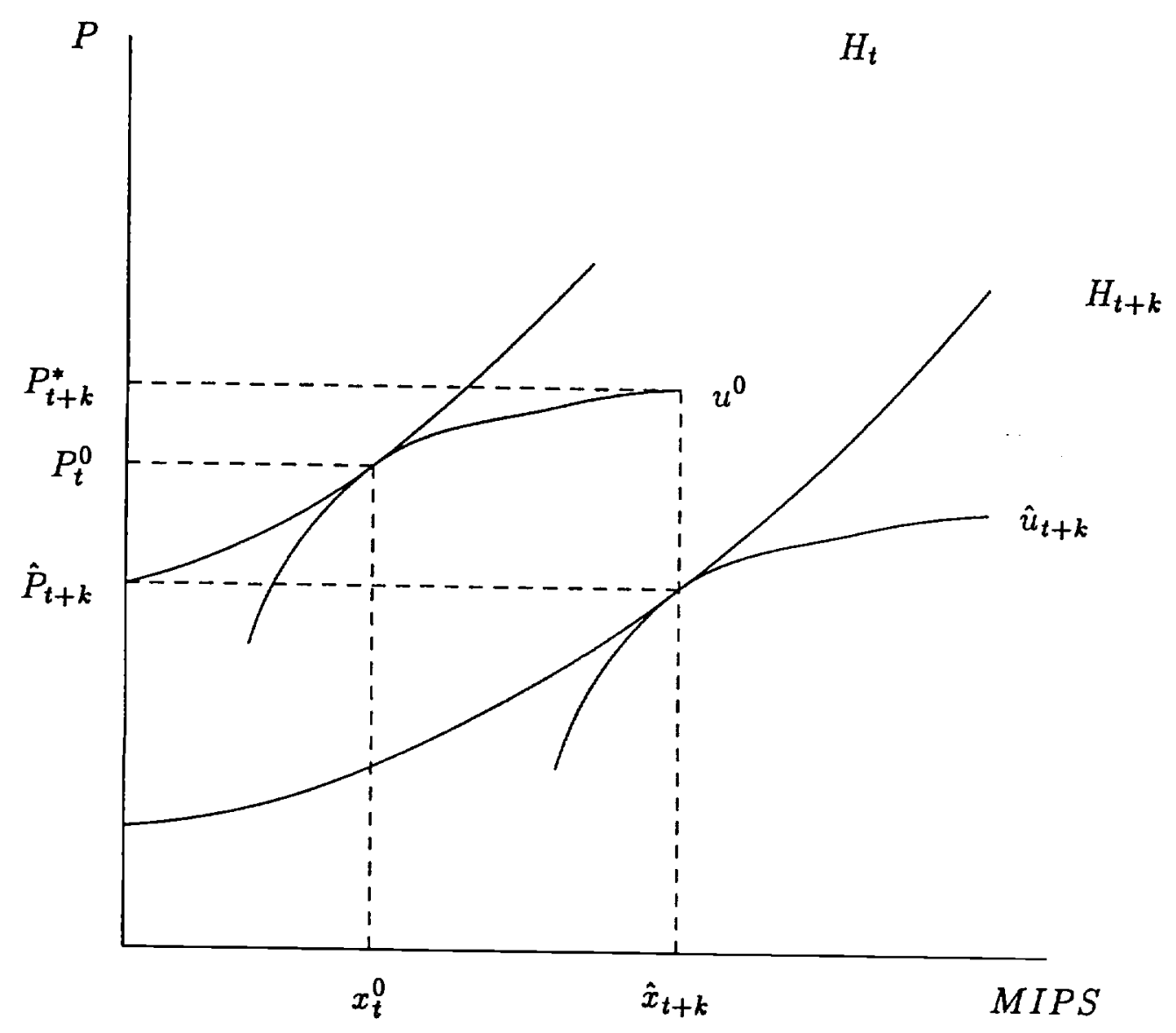


Figure 3.4

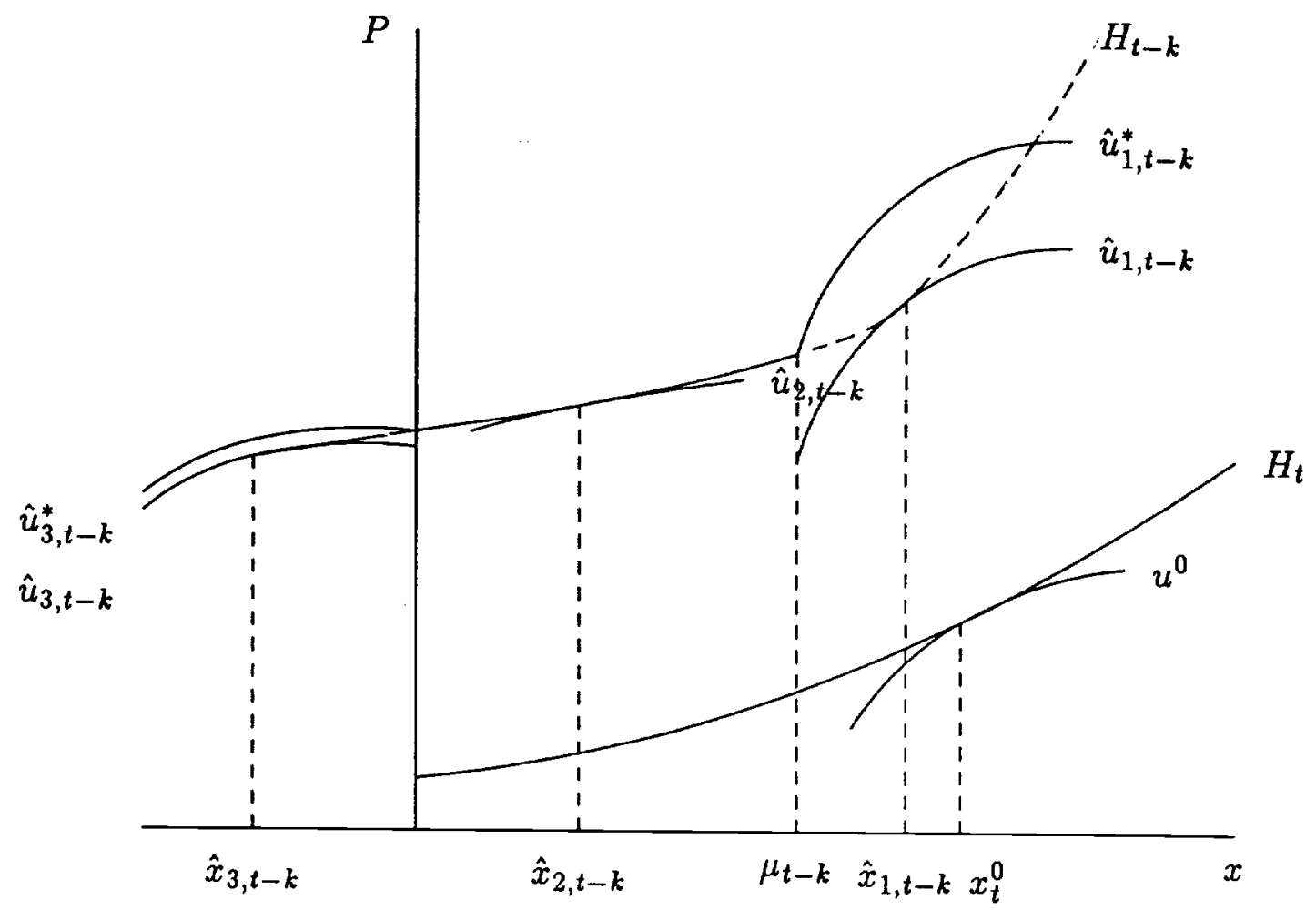


Figure 4.1

One Variable Hedonic Surfaces

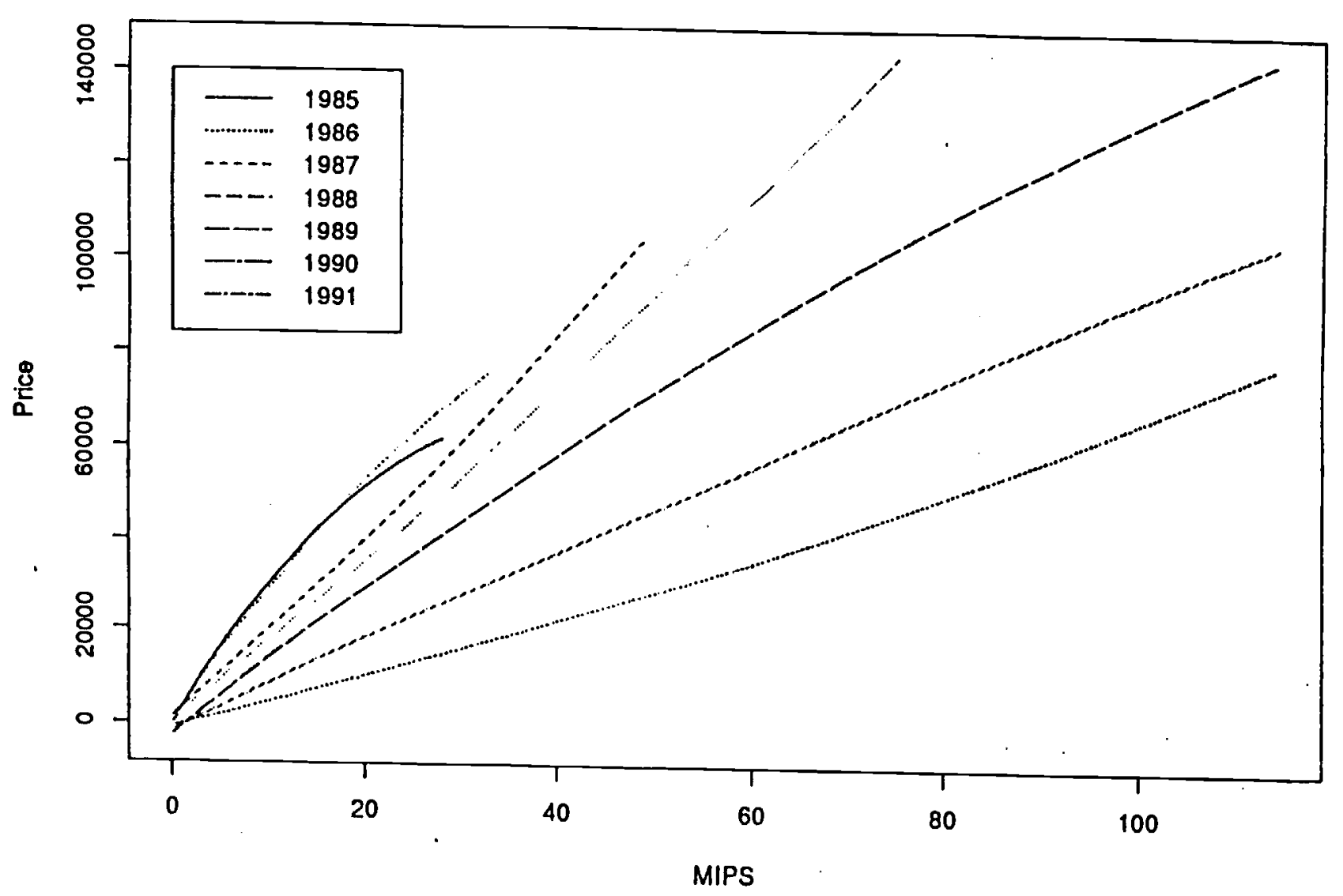


Figure 4.2

Box-Plot of MIPS-All Data

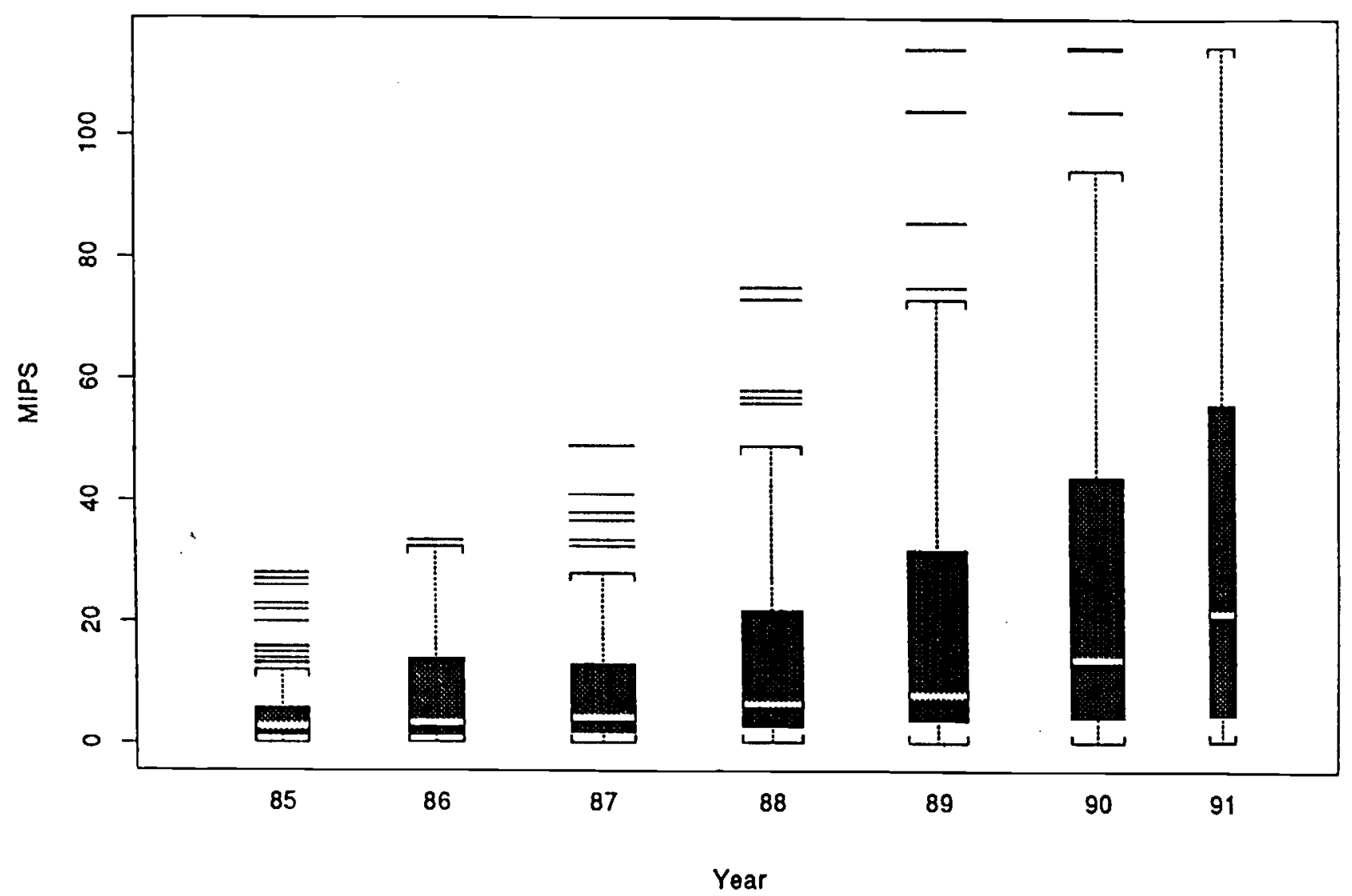


Figure 4.3

Box-Plot of MIPS-IBM Data

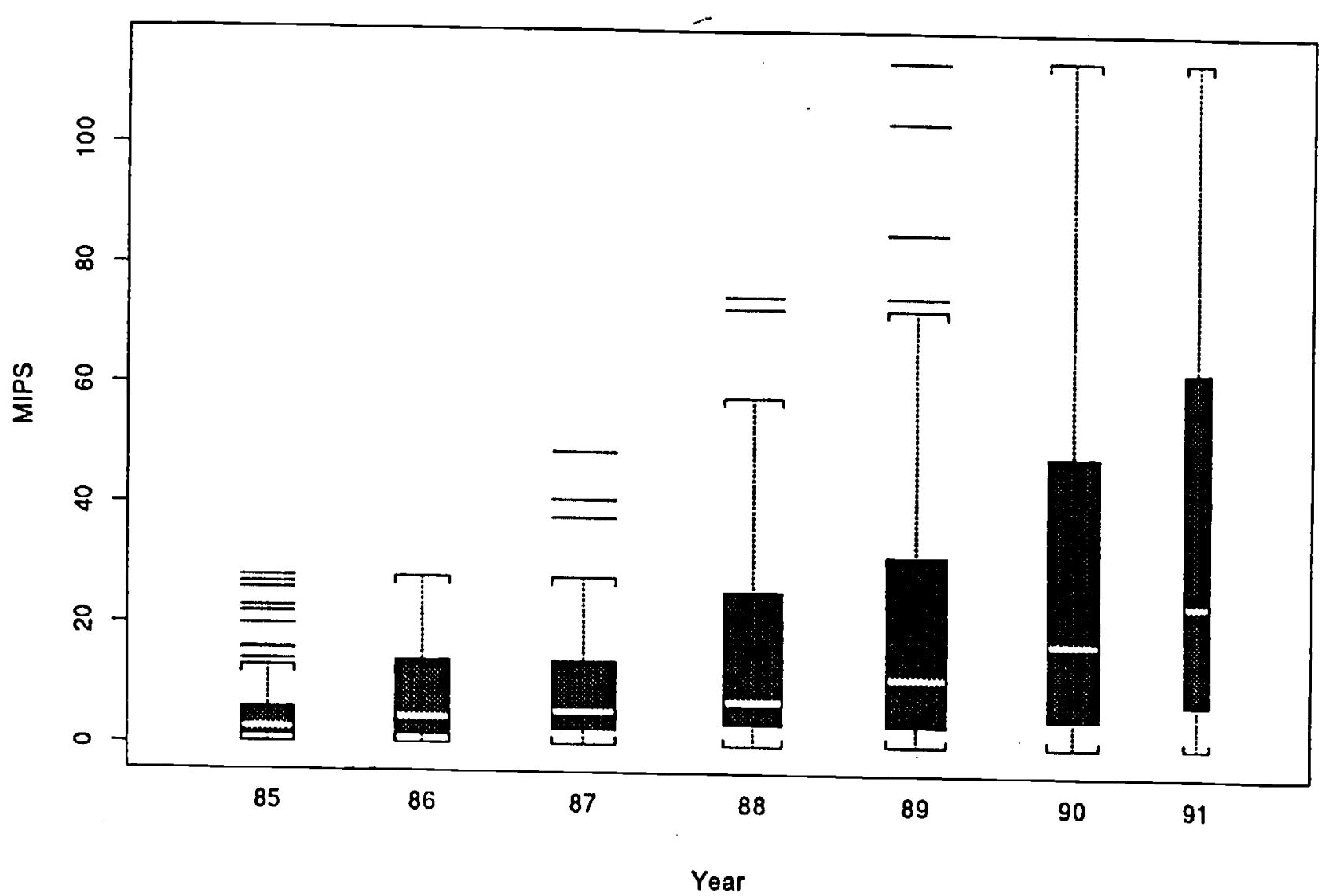


Figure 4.4

Box-Plot of Minimum Memory-All Data

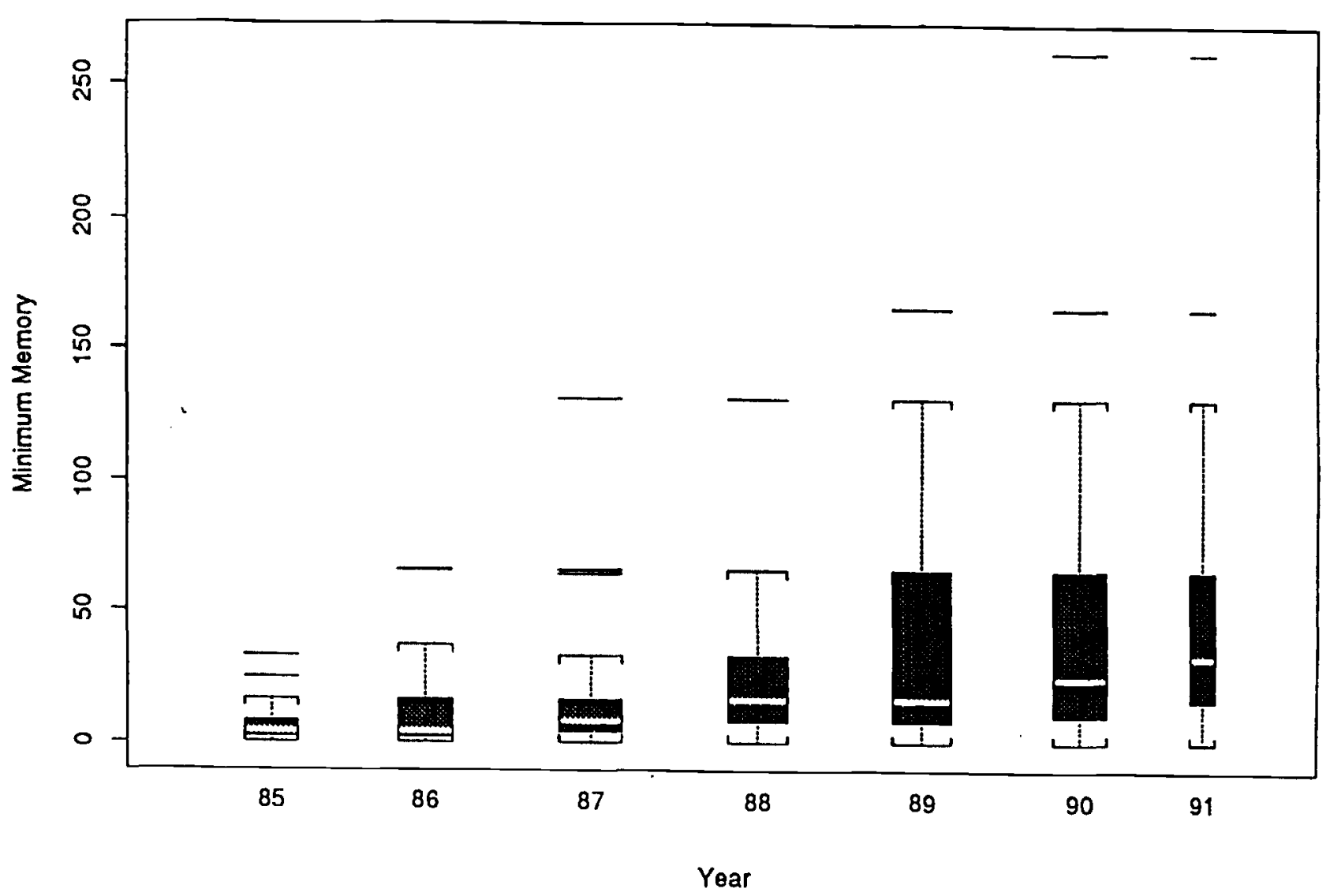


Figure 4.5

Box-Plot of Maximum Memory-All Data

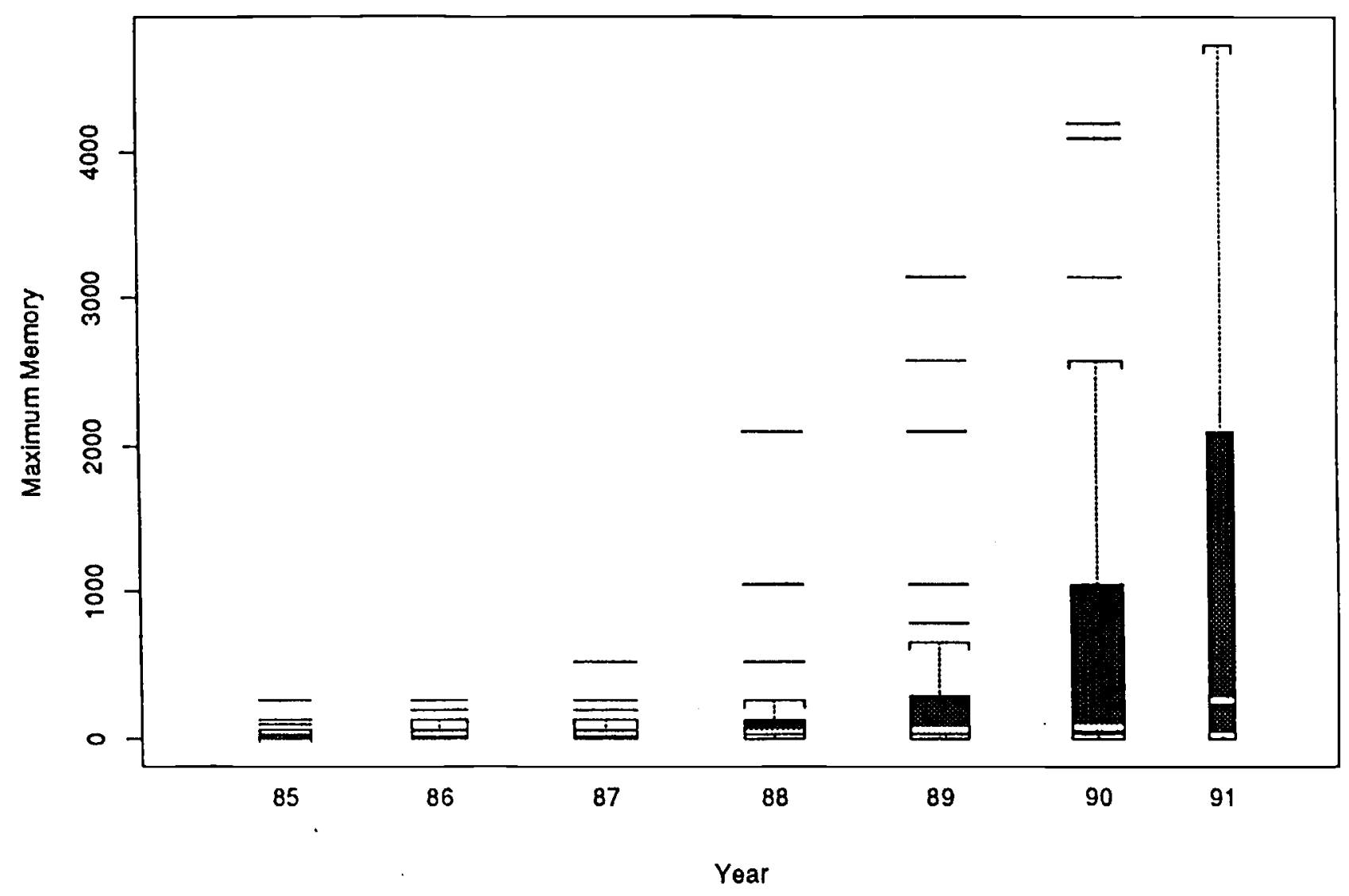

